\title{
Role of Q52 in Catalysis of Decarboxylation and Transamination in Dialkylglycine Decarboxylase ${ }^{\dagger}$
}

\author{
Emily J. Fogle, ${ }^{\ddagger}$ Wenshe Liu, ${ }^{*}$ See-Tarn Woon, ${ }^{\S}$ John W. Keller, ${ }^{\S}$ and Michael D. Toney*,; \\ Department of Chemistry, University of California, Davis, California 95616, and Department of Chemistry and Biochemistry, \\ University of Alaska, Fairbanks, Alaska 99775
}

Received July 26, 2005; Revised Manuscript Received October 6, 2005

\begin{abstract}
Dialkylglycine decarboxylase (DGD) is a pyridoxal phosphate dependent enzyme that catalyzes both decarboxylation and transamination in its normal catalytic cycle. DGD uses stereoelectronic effects to control its unusual reaction specificity. X-ray crystallographic structures of DGD suggest that Q52 is important in maintaining the substrate carboxylate in a stereoelectronically activated position. Here, the X-ray structures of the Q52A mutant and the wild type (WT) DGD-PMP enzymes are presented, as is the analysis of steady-state and half-reaction kinetics of three Q52 mutants (Q52A, Q52I, and Q52E). As expected if stereoelectronic effects are important to catalysis, the steady-state rate of decarboxylation for all three mutants has decreased significantly compared to that of WT. Q52A exhibits an $\sim 85$-fold decrease in $k_{\text {cat }}$ relative to that of WT. The rate of the decarboxylation half-reaction decreases $\sim 10^{5}$-fold in Q52I and $\sim 10^{4}$-fold in Q52E compared to that of WT. Transamination half-reaction kinetics show that Q52A and Q52I have greatly reduced rates compared to that of WT and are seriously impaired in pyridoxamine phosphate (PMP) binding, with $K_{\mathrm{PMP}}$ at least 50-100-fold greater than that of WT. The larger effect on the rate of L-alanine transamination than of pyruvate transamination in these mutants suggests that the rate decrease is the result of selective destabilization of the PMP form of the enzyme in these mutants. Q52E exhibits near-WT rates for transamination of both pyruvate and L-alanine. Substrate binding has been greatly weakened in Q52E with apparent dissociation constants at least 100-fold greater than that of WT. The rate of decarboxylation in Q52E allows the energetic contribution of stereoelectronic effects, $\Delta G_{\text {stereoelectronic }}$, to be estimated to be $-7.3 \mathrm{kcal} / \mathrm{mol}$ for DGD.
\end{abstract}

Pyridoxal phosphate (PLP) ${ }^{1}$ dependent enzymes constitute a large and well-characterized group of enzymes, catalyzing many different types of chemistry at the $\alpha$-, $\beta$-, and $\gamma$-carbons of amine and amino acid substrates. Despite the diversity of chemistry catalyzed by PLP dependent enzymes as a group, individual enzymes exhibit remarkably high reaction specificities. In contrast, model studies show that PLP alone is capable of nonenzymatically catalyzing multiple reaction types with a given substrate. For example, reaction of PLP with serine results in transamination, $\beta$-elimination, and retroaldol cleavage (1). As an explanation for the high enzymatic versus nonenzymatic specificity, it was proposed by $\mathrm{Du}-$ nathan (2) that PLP dependent enzymes use stereoelectronic effects to control reaction specificity. He proposed that the scissile bond is aligned parallel to the p orbitals of the extended $\pi$ system of the aldimine, providing maximal orbital

\footnotetext{
† Supported by Grant GM54779 from the National Institutes of Health.

* To whom correspondence should be addressed. E-mail: mdtoney@ucdavis.edu. Fax: (530) 752-8995. Telephone: (530) 7545282.

$\doteqdot$ University of California.

$\S$ University of Alaska.

${ }^{1}$ Abbreviations: DGD, 2,2-dialkylglycine decarboxylase; PLP, pyridoxal $5^{\prime}$-phosphate; PMP, pyridoxamine $5^{\prime}$-phosphate; WT, wildtype DGD; $2^{\circ} \mathrm{ADH}$, NADPH dependent secondary alcohol dehydrogenase; AIB, 2-aminoisobutyrate; TEA, triethanolamine; MES, morpholinoethanesulfonic acid.
}

Scheme 1

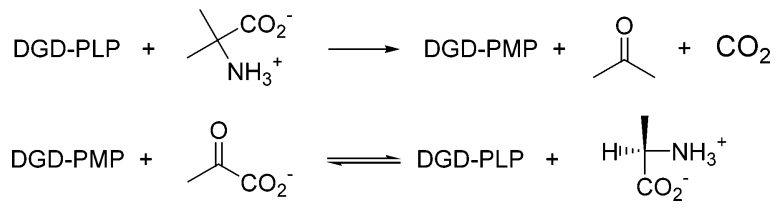

overlap and resonance stabilization in the transition state, therefore accelerating the rate of bond cleavage for the activated bond compared to the other bonds to $\mathrm{C}_{\alpha}$.

Stereoelectronic effects have been investigated in simple organic systems both experimentally and computationally $(3-7)$. However, there has been little direct experimental evidence for stereoelectronic effects in enzymatic systems. Examples include the observation that the $\mathrm{C}_{\alpha}-\mathrm{CH}_{3}$ bond of 2-methylaspartate is aligned parallel to the $\pi$ system in the active site of aspartate aminotransferase (8), the fact that arginine decarboxylase is sensitive to the size of the substrate side chain (9), and the observed specificity of $\alpha$-proton exchange of amino acids in tryptophan synthase (10). Dialkylglycine decarboxylase (DGD) has also been shown to employ stereoelectronic effects, using kinetic (11), X-ray crystallographic (12), and computational (13) methods.

DGD is an unusual PLP dependent enzyme that catalyzes decarboxylation and transamination in its normal catalytic cycle (Scheme 1). A functional active site model based on the unusual reaction specificity of DGD and stereoelectronic 


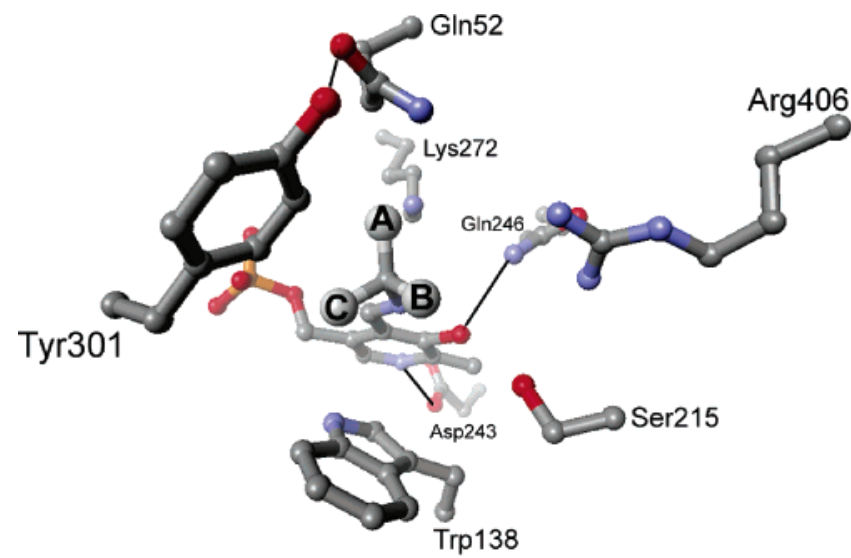

FIGURE 1: Active site model for DGD indicating the position of the binding subsites $(\mathrm{A}-\mathrm{C})$.

control of reaction specificity has been proposed (14) and validated (11). In this model, there are three subsites, the A subsite, near Q52 and K272, the stereoelectronically activated position in which all bond breaking and making occur; the B subsite, near R406 and S215, which can bind a carboxylate; and the C subsite, near M141 (Figure 1). On the basis of X-ray crystallographic studies, Q52 has been proposed to hydrogen bond with the substrate carboxylate, thereby helping to keep it in the stereoelectronically activated A subsite (12); Q52 plays no other obvious role in catalysis. To the degree that stereoelectronic effects accelerate the rate of decarboxylation in DGD, mutation of Q52 to amino acids with side chains that no longer stabilize the carboxylate in the A subsite or actively prevent binding of the carboxylate in this subsite is predicted to yield reduced rates of decarboxylation.

Here, a series of Q52 mutants was made and characterized to explore the role of this residue in catalysis, particularly with regard to stereoelectronic control of reaction specificity. Steady-state and half-reaction kinetics are presented for Q52A, Q52I, and Q52E which demonstrate that Q52 plays a major role in stabilizing the carboxylate in the A subsite and that such positioning is necessary for efficient catalysis of decarboxylation. It is shown here that Q52 is important in selectively lowering the energy of the DGD-PMP enzyme relative to that of the DGD-PLP enzyme. A structural rationale for this finding is proposed on the basis of X-ray crystallographic structures of Q52A with PLP bound and WT with PMP bound. Finally, work with Q52E allows an estimation of the energetic contribution of stereoelectronic effects to catalysis in DGD.

\section{EXPERIMENTAL PROCEDURES}

Materials. All commercial chemicals were purchased from Sigma. PMP was synthesized according to a literature procedure (15). Briefly, $1 \mathrm{~g}$ of PLP was dissolved in $40 \mathrm{~mL}$ of methanol, $6 \mathrm{~mL}$ of ammonium hydroxide added, and the reaction mixture stirred for $60 \mathrm{~min}$ at room temperature. Sodium borohydride (1.2 equiv) was added and the reaction mixture stirred at room temperature for $60 \mathrm{~min}$. The methanol was removed by rotorary evaporation, and the product was redissolved in water. The mixture was acidified to $\mathrm{pH} 2.0$ with concentrated $\mathrm{HCl}$, loaded onto Amberlite IRP-64 cationexchange resin, and eluted with water. The fractions containing PMP, as determined by ninhydrin, were pooled and concentrated to dryness. HPLC analysis showed no contamination by PLP or other vitamin $\mathrm{B}_{6}$ derivatives.

Preparation of Q52 Mutants. The pBTac (Boehringer Mannheim) plasmid containing the Q52A DGD mutant was employed. The Quikchange site-directed mutagenesis protocol (Stratagene) was used to introduce the desired mutations. The Q52I mutation was introduced with the following primer pair: 5'-CAC GTC GGG GAT TAT GAG CGC GGT GCT CGG CC-3' and 5'-GGC CGA GCA CCG CGC TCA TAA TCC CCG ACG TG-3' (with the converted codon underlined). The Q52E mutation was introduced with the following primers: 5'-CAC GTC GGG GGA GAT GAG CGC GGT GCT CGG CC-3' and 5'-GGC CGA GCA CCG CGC TCA TCT CCC CCG ACG TG-3' (with the converted codon underlined). Because of the high GC content of the DGD gene, it was necessary to use 5\% (v/v) DMSO in the PCRs. After transformation into Escherichia coli JM109 using standard procedures (16), the mutant plasmid was isolated using a commercial kit (Qiagen) and the full coding region sequenced to confirm the desired mutation had been incorporated.

Expression and Purification of Q52 Mutants. For overexpression, $750 \mathrm{~mL}$ of TB growth medium was inoculated with a $5 \mathrm{~mL}$ overnight culture and grown at $37^{\circ} \mathrm{C}$ until the $\mathrm{OD}_{600}$ reached 0.4 . The cells were placed on ice for $20 \mathrm{~min}$; expression was induced with IPTG at a final concentration of $500 \mu \mathrm{M}$, and cells were grown at $33^{\circ} \mathrm{C}$ for $8-10 \mathrm{~h}$. The cells were pelleted by centrifugation, resuspended in lysis buffer [20 mM TEA-HCl (pH 7.8), 50 mM KCl, $20 \mu \mathrm{M}$ PLP, and $1 \mathrm{M}$ ammonium sulfate], and stored overnight at -80 ${ }^{\circ} \mathrm{C}$. The thawed cell suspension was sonicated and the cell debris removed by centrifugation. The cell free extract was brought to $2.2 \mathrm{M}$ ammonium sulfate and stirred at $4{ }^{\circ} \mathrm{C}$ for $1 \mathrm{~h}$. The precipitated protein was removed by centrifugation, and the pellet was dissolved and dialyzed into $20 \mathrm{mM}$ TEA$\mathrm{HCl}(\mathrm{pH} 7.8)$ and $20 \mu \mathrm{M}$ PLP. The protein solution was loaded onto a $50 \mathrm{~mL}$ Q-Sepharose Fast Flow column (Pharmacia) and eluted with a gradient of 100 to $400 \mathrm{mM}$ $\mathrm{KCl}$ in $20 \mathrm{mM}$ TEA-HCl (pH 7.8). The fractions were analyzed by SDS-PAGE and those containing DGD pooled, concentrated, and brought to $1 \mathrm{M}$ in $\mathrm{KCl}$. This solution was loaded onto a $50 \mathrm{~mL}$ phenyl-Sepharose column (Pharmacia) and the protein eluted with a gradient of 1 to $0 \mathrm{M} \mathrm{KCl}$ in 20 $\mathrm{mM}$ TEA-HCl ( $\mathrm{pH}$ 7.8). The purest fractions, as judged by SDS-PAGE, were pooled, concentrated, and dialyzed into $50 \mathrm{mM}$ TEA-succinate $(\mathrm{pH}$ 7.8), $50 \mathrm{mM}$ dipotassium succinate, and $20 \mu \mathrm{M}$ PLP. The protein was aliquoted, flashfrozen, and stored at $-80{ }^{\circ} \mathrm{C}$. The protein concentration was determined using both the extinction coefficient determined for DGD and the Lowry protein assay kit from Bio-Rad with IgG as a standard.

Crystallization, X-ray Diffraction Data Collection, and Structural Refinement of $Q 52 A$. The initial trials to crystallize Q52A were carried out via the hanging drop vapor diffusion method using crystallization conditions similar to those used to crystallize WT DGD (14). Drops of $1 \mu \mathrm{L}$ containing 20 $\mathrm{mg} / \mathrm{mL}$ protein, $5 \mathrm{mM}$ potassium phosphate $(\mathrm{pH} 7.5)$, and $20 \mu \mathrm{M}$ PLP were mixed with $1 \mu \mathrm{L}$ of a reservoir solution containing 15\% PEG4000 (w/v), 15 mM MES-KOH ( $\mathrm{pH}$ 6.4), 75-200 mM sodium pyruvate, and $20 \mu \mathrm{M}$ PLP, and equilibrated against $1 \mathrm{~mL}$ of this reservoir solution. However, the protein precipitated under these conditions. Crystals were 


\begin{tabular}{|c|c|c|}
\hline & Q52A & DGD-PMP \\
\hline \multicolumn{3}{|l|}{ unit cell dimensions } \\
\hline$a=b, c(\AA)$ & $150.04,84.43$ & $151.65,85.04$ \\
\hline$\alpha=\beta, \gamma(\operatorname{deg})$ & $90.0,120.0$ & $90.0,120$ \\
\hline space group & $P 6_{4} 22$ & $P 6422$ \\
\hline no. of monomers per asymmetric unit & 1 & 1 \\
\hline resolution range $(\AA)$ & $50.0-2.90$ & $50.0-2.00$ \\
\hline$R_{\mathrm{sym}}^{a}(\%)$ & $8.9(25.2)$ & $7.2(27.8)$ \\
\hline$\langle I\rangle / \sigma\langle I\rangle$ & $5.96(2.0)$ & $7.8(2.0)$ \\
\hline no. of reflections & 178045 & 505410 \\
\hline redundancy & 13.7 & 13.0 \\
\hline completeness $(\%)$ & 99.9 & 98.8 \\
\hline$R_{\text {factor }}^{b}(\%)$ & 0.209 & 0.199 \\
\hline$R_{\text {free }}^{c}(\%)$ & 0.266 & 0.237 \\
\hline no. of protein atoms & 3247 & 3247 \\
\hline no. of cofactor atoms & 15 & 16 \\
\hline no. of water molecules & 33 & 291 \\
\hline \multicolumn{2}{|l|}{ mean $B$ factor $\left(\AA^{2}\right)$} & \\
\hline main chain & 25.2 & 21.7 \\
\hline side chains & 26.6 & 25.2 \\
\hline solvent & 19.4 & 32.4 \\
\hline \multicolumn{3}{|l|}{ rmsd from ideality } \\
\hline bond distances $(\AA)$ & 0.007 & 0.016 \\
\hline bond angles (deg) & 1.33 & 1.73 \\
\hline \multicolumn{3}{|c|}{$\begin{array}{l}{ }^{a} R_{\text {sym }}=\sum \sum_{j}\left|I_{j}(h k l)-\langle I(h k l)\rangle\right| / \sum \sum_{j}|I(h k l)| \text {, where } I_{j} \text { is the measured } \\
\text { intensity of reflection } j \text { and }\langle I\rangle \text { is the mean intensity over } j \text { reflections. } \\
n R_{\text {factor }}=\sum|| F_{\text {obs }}(h k l)|-| F_{\text {calc }}(h k l)|| / \sum\left|F_{\text {obs }}(h k l)\right| \text {, where } F_{\text {obs }} \text { and } F_{\text {calc }} \\
\text { are observed and calculated structure factors, respectively. No } \sigma \text { cutoff } \\
\text { was applied. }{ }^{c} R_{\text {free }} \text { is the } R \text { factor calculated with } 5 \% \text { of the data that } \\
\text { were not used for refinement. }\end{array}$} \\
\hline
\end{tabular}

obtained by utilizing WT DGD crystals as microseeds (17). These Q52A crystals microseeded with WT were then used as microseeds for further crystallization. This eliminated WT DGD contamination, and large crystals were obtained. Crystals obtained in this way appeared in several hours at room temperature and grew to maximal sizes in a week. Before being mounted onto the X-ray diffractometer, the crystals were soaked in a stabilizing solution containing $30 \%$ PEG4000, $15 \mathrm{mM}$ MES-KOH (pH 6.4), and $20 \mu \mathrm{M}$ PLP for 1 day and then soaked in a cryo-solution containing $30 \%$ PEG4000, $15 \mathrm{mM}$ MES-KOH (pH 6.4), $20 \mu \mathrm{M}$ PLP, and $26 \%$ glycerol for $2 \mathrm{~h}$. The diffraction data were collected at $100 \mathrm{~K}$ on a Bruker $\mathrm{CCD}$ detector using $\mathrm{Cu} \mathrm{K} \alpha$ radiation. Reflection intensities were integrated and merged using PROTEUM. The merged data were reduced to structure factors using the combination of SCALEPACK2MTZ, CAD, and TRUNCATE programs from the CCP4 program suite (18). The WT DGD $-\mathrm{K}^{+}$structure (14) in which the MES ligand, PLP cofactor, metal ions, and water molecules were removed was used as the search model for molecular replacement. CNS was used throughout for molecular replacement and structural refinement. Model building was conducted with O. Refinement was monitored using $R_{\text {free }}$ calculated from $5 \%$ of the data. The data collection and refinement statistics are given in Table 1. The coordinates for the Q52A structure have been deposited in the Protein Data Bank as entry $1 \mathrm{Z} 3 \mathrm{Z}$.

Crystallization, X-ray Diffraction Data Collection, and Structural Refinement of the WT DGD-PMP Enzyme. The crystals of the DGD-PMP enzyme were prepared by soaking WT DGD-PLP crystals obtained as previously described (14) in a stabilizing buffer containing 30\% PEG4000, 15 $\mathrm{mM}$ MES-KOH (pH 6.4), and $1 \mathrm{mM}$ AIB for $30 \mathrm{~min}$ to convert PLP to PMP in the enzyme active site. These crystals were then soaked in a buffer containing 30\% PEG4000, 15\% MES-KOH (pH 6.4), and $10 \mathrm{mM}$ PMP for $2 \mathrm{~h}$, and finally soaked in a cryo-protecting solution containing 30\% PEG4000, $15 \mathrm{mM}$ MES-KOH (pH 6.4), $10 \mathrm{mM}$ AIB, and $26 \%$ glycerol for 1 day. The diffraction data for the DGD-PMP enzyme were collected and processed as described above for Q52A. The WT DGD $-\mathrm{K}^{+}$structure in which all ligands and waters were deleted was used as a starting model for molecular replacement. CNS and $\mathrm{O}$ were utilized to carry out the structure refinement and model building. The data collection and refinement statistics are given in Table 1. The DGDPMP PDB entry is 1ZC9.

Steady-State Assays. AIB decarboxylation was followed by coupling acetone produced from oxidative decarboxylation of AIB to the $2^{\circ} \mathrm{ADH}$ reaction as previously described (11). Loss of NADPH absorbance at $340 \mathrm{~nm}$ was followed on a Kontron UVIKON 9420 apparatus. Reaction mixtures contained $100 \mathrm{mM}$ TEA-succinate $(\mathrm{pH} 7.8), 100 \mathrm{mM}$ dipotassium succinate, 1 unit $/ \mathrm{mL} 2^{\circ} \mathrm{ADH}, 300 \mu \mathrm{M}$ PLP, and $300 \mu \mathrm{M}$ NADPH. AIB stock solutions were prepared in 20 $\mathrm{mM}$ TEA-succinate ( $\mathrm{pH} 7.8$ ), and the $\mathrm{pH}$ of the solution was adjusted to 7.8. Sodium pyruvate was used as the $\alpha$-keto acid. Initial rates were plotted versus substrate concentration and fitted to the Michaelis-Menten equation.

Steady-state transamination using L-alanine and $\alpha$-ketocaproate was followed by coupling the formation of pyruvate to alanine dehydrogenase. Alanine dehydrogenase shows no significant activity with $\alpha$-ketocaproate at the enzyme and substrate concentrations that were used. The reaction was monitored by the decrease in NADH absorbance at $380 \mathrm{~nm}$ where there is less interference from absorbance due to the $\alpha$-keto acid. Reaction mixtures contained $50 \mathrm{mM}$ TEAsuccinate (pH 7.8), $50 \mathrm{mM}$ dipotassium succinate, $20 \mu \mathrm{M}$ PLP, and $10 \mathrm{mM}$ ammonium succinate. L-Alanine and $\alpha$-ketocaproate stock solutions were prepared in $20 \mathrm{mM}$ TEA-succinate, and the $\mathrm{pH}$ was adjusted to 7.8. Initial rates were plotted versus substrate concentration and fitted to the Michaelis-Menten equation.

Q52A Steady-State Kinetics. The steady-state kinetic parameters $\left(k_{\text {cat }}, K_{\mathrm{AIB}}\right.$, and $\left.K_{\text {pyruvate }}\right)$ were determined using the $2^{\circ} \mathrm{ADH}$-coupled assay. Briefly, one substrate was held at a saturating concentration (AIB at $500 \mathrm{mM}$; pyruvate at 2 $\mathrm{mM}$ ) while the other was varied. $K_{\text {PLP }}$ was determined by varying the PLP concentration from 0 to $400 \mu \mathrm{M}$ while holding the AIB concentration at $500 \mathrm{mM}$ and the pyruvate concentration at $2 \mathrm{mM}$.

Spectral Kinetic Analysis of the Q52A AIB Decarboxylation Half-Reaction. The AIB decarboxylation half-reaction was followed by rapidly mixing Q52A-PLP ( $20 \mu \mathrm{M}$ enzyme in $50 \mathrm{mM}$ TEA-succinate, $50 \mathrm{mM}$ dipotassium succinate, and $10 \mu \mathrm{M}$ PLP) against an AIB solution prepared in the same buffer in an Applied Photophysics SX.18MV-R stopped-flow spectrophotometer. Coenzyme spectral changes were followed from 200 to $800 \mathrm{~nm}$ using a diode array detector. The data from 300 to $600 \mathrm{~nm}$ were globally fit using Specfit to a four-exponential model, which was the best fit as judged by the residuals.

Spectral Kinetic Analysis of the Q52A and Q52I L-Alanine Transamination Half-Reaction. Coenzyme spectral changes from 300 to $600 \mathrm{~nm}$ were followed using a Hewlett-Packard $8453 \mathrm{UV}$ - vis spectrophotometer. Reactions were carried out 
in $50 \mathrm{mM}$ TEA-succinate $(\mathrm{pH} 7.8), 50 \mathrm{mM}$ dipotassium succinate, $10 \mu \mathrm{M}$ PLP, $20 \mu \mathrm{M}$ PLP-bound enzyme, and varying concentrations of L-alanine. The spectral data were globally fitted to an appropriate model using Specfit. For Q52A, a one-exponential model was used; for Q52I, a twoexponential model fit the data best. In each case, the apparent rate constants were plotted versus substrate concentration and fitted to eq 1 .

$$
k_{\mathrm{obs}}=\frac{k_{\mathrm{max}}[\mathrm{AIB}]}{K_{\mathrm{app}}+[\mathrm{AIB}]}+\text { offset }
$$

Spectral Kinetic Analysis of the Q52A and Q52I Pyruvate Transamination Half-Reaction. Apoenzyme was prepared by dialyzing the holoenzyme against $10 \mathrm{mM}$ hydroxylamine, and $100 \mathrm{mM}$ TEA-succinate ( $\mathrm{pH}$ 7.8), followed by extensive dialysis into $100 \mathrm{mM}$ TEA-succinate (pH 7.8). The formation of the apoenzyme was confirmed by wavelength scans showing no coenzyme absorbance above $\sim 300 \mathrm{~nm}$. The protein concentration of the apoenzyme solution was determined using a Bio-Rad Lowry protein concentration kit with $\mathrm{IgG}$ as a standard. Apoenzyme was incubated with varying concentrations of PMP for $1 \mathrm{~h}$ at room temperature to ensure binding of PMP to the enzyme had come to equilibrium. Incubation for longer periods showed no increase in activity. After incubation, pyruvate was added to a final concentration of $100 \mathrm{mM}$ and the reaction followed at $410 \mathrm{~nm}$. The rate of nonenzymatic transamination between pyruvate and PMP under the same conditions was measured and subtracted from the rate of total transamination seen in the enzymatic sample. The resulting data were fitted to a burst equation (eq 2).

$$
P=A\left(1-\mathrm{e}^{-k_{\text {burst }}{ }^{t}}\right)+k_{\text {cat }}
$$

Spectral Kinetic Analysis of the Q52I and Q52E AIB Decarboxylation Half-Reaction. Coenzyme spectral changes were followed as in the L-alanine transamination half-reaction of Q52A and Q52I. Reactions were carried out in $20 \mu \mathrm{M}$ PLP-bound enzyme, $50 \mathrm{mM}$ TEA-succinate, $50 \mathrm{mM}$ dipotassium succinate, and $20 \mu \mathrm{M}$ PLP. The appropriate amount of a stock AIB solution (prepared in $20 \mathrm{mM}$ TEA-succinate with the $\mathrm{pH}$ adjusted to 7.8) was added to initiate the reaction. The multiwavelength data fit best to a two-exponential model for both Q52I and Q52E. The apparent rate constants for the Q52I data were fitted to eq 1.

Spectral Kinetic Analysis of the Q52E L-Alanine Transamination Half-Reaction. The L-alanine transamination halfreaction was followed by rapidly mixing Q52E-PLP (20 $\mu \mathrm{M}$ enzyme in $50 \mathrm{mM}$ TEA-succinate, $50 \mathrm{mM}$ dipotassium succinate, and $10 \mu \mathrm{M}$ PLP) against an L-alanine solution prepared in the same buffer. Data were collected in the stopped-flow spectrophotometer as described above and globally fitted to a two-exponential model.

Spectral Kinetic Analysis of the Q52E Pyruvate Transamination Half-Reaction. Apo-Q52E was prepared as described above. Q52E-PMP was made by incubating 20 $\mu \mathrm{M}$ apo-Q52E with $50 \mathrm{mM}$ TEA-succinate (pH 7.8), $50 \mathrm{mM}$ dipotassium succinate, and varying concentrations of PMP at room temperature for $1 \mathrm{~h}$. Incubation for longer periods showed no increase in activity. Q52E-PMP was mixed against a pyruvate solution prepared in $50 \mathrm{mM}$ TEAsuccinate, $50 \mathrm{mM}$ dipotassium succinate, and varying concentrations of PMP. The pyruvate solutions were prepared immediately before being used to prevent nonenzymatic transamination.

$K_{\mathrm{PMP}}$ for Q52E was estimated by incubating apoenzyme with varying concentrations of PMP (from $20 \mu \mathrm{M}$ to $6 \mathrm{mM}$ ) in $50 \mathrm{mM}$ TEA-succinate and $50 \mathrm{mM}$ dipotassium succinate followed by rapid stopped-flow mixing with $100 \mathrm{mM}$ pyruvate prepared in the same buffer. Data were collected between 375 and $600 \mathrm{~nm}$ and fitted to a two-exponential model.

Reactions with varying pyruvate concentrations were performed with $20 \mu \mathrm{M}$ enzyme incubated with $50 \mathrm{mM}$ TEAsuccinate ( $\mathrm{pH} 7.8), 50 \mathrm{mM}$ dipotassium succinate, and $1 \mathrm{mM}$ PMP (>10K $\mathrm{PMP})$.

HPLC Detection of PMP Formation in the Q52E AIB Decarboxylation Half-Reaction. Time points were taken from a reaction mixture containing $20 \mu \mathrm{M}$ Q52E-PLP, $50 \mathrm{mM}$ TEA-succinate, $50 \mathrm{mM}$ dipotassium succinate, $20 \mu \mathrm{M}$ PLP, and $600 \mathrm{mM}$ AIB. At appropriate times, ranging from 60 to $7000 \mathrm{~s}$, a $100 \mu \mathrm{L}$ aliquot was removed and quenched with 2 $\mu \mathrm{L}$ of glacial acetic acid. The precipitated enzyme was removed by centrifugation. PMP was identified using a literature HPLC method (19) with some modifications on a Supelco C18 HPLC column (Supelcosil LC-18). Briefly, a linear gradient was run between buffer A and B over 10 min, followed by $100 \%$ B for a further $5 \mathrm{~min}$ at flow rate of 0.7 $\mathrm{mL} / \mathrm{min}$. Buffer A consisted of 10\% propanol (v/v), 0.09\% acetic acid (v/v), and $4 \mathrm{mM}$ heptanesulfonic acid. Buffer B consisted of $10 \%$ propanol (v/v) and $0.09 \%$ acetic acid (v/ v). PMP was monitored at $330 \mathrm{~nm}$.

\section{RESULTS}

$X$-ray Crystallographic Strctures of Q52A-PLP and WT $D G D-P M P$. The refined Q52A-PLP structure contains a MES ligand at the active site, a potassium ion close to the active site, and a sodium ion on the surface of the protein that are all similar to those of WT DGD. Although the omit electron density map clearly indicates the existence of a water molecule filling the space created by the Q52A mutation (Figure 3B), the temperature factor of this water molecule (43.9) is significantly higher than the average temperature factor of the peptide (25.8) or solvent molecules (19.4). The Q52A mutation, which eliminates a hydrogen bond that normally helps to hold Y301 in place (14), and the mobility of the water molecule taking the place of the Q52 side chain lead to a relatively high mobility of the Y301 side chain (average $B=37$ ). The superimposition of the Q52A dimer and WT dimer gives a pairwise rms deviation of $0.37 \AA$ with no significant differences other than the site of mutation.

The overall structure of DGD-PMP is very similar to that of DGD-PLP except for the different cofactor forms and the absence of a MES ligand bound at the active site of DGD-PMP. To prevent steric clash with K272, PMP reorients, tilting $\sim 16^{\circ}$ forward with respect to the internal aldimine formed between PLP and K272 in DGD-PLP (Figure 2A). The amino group of PMP forms a strong hydrogen bond to the amino nitrogen of K272 and also shares a hydrogen bond with a water molecule that fills the position occupied by the MES ligand in DGD-PLP (Figure 3A).

Steady-State Kinetics. The kinetic parameters for Q52A and WT are given in Table 2. The Q52A mutant shows an 85 -fold decrease in $k_{\text {cat }}$ relative to that of WT; $K_{\mathrm{AIB}}$ has 

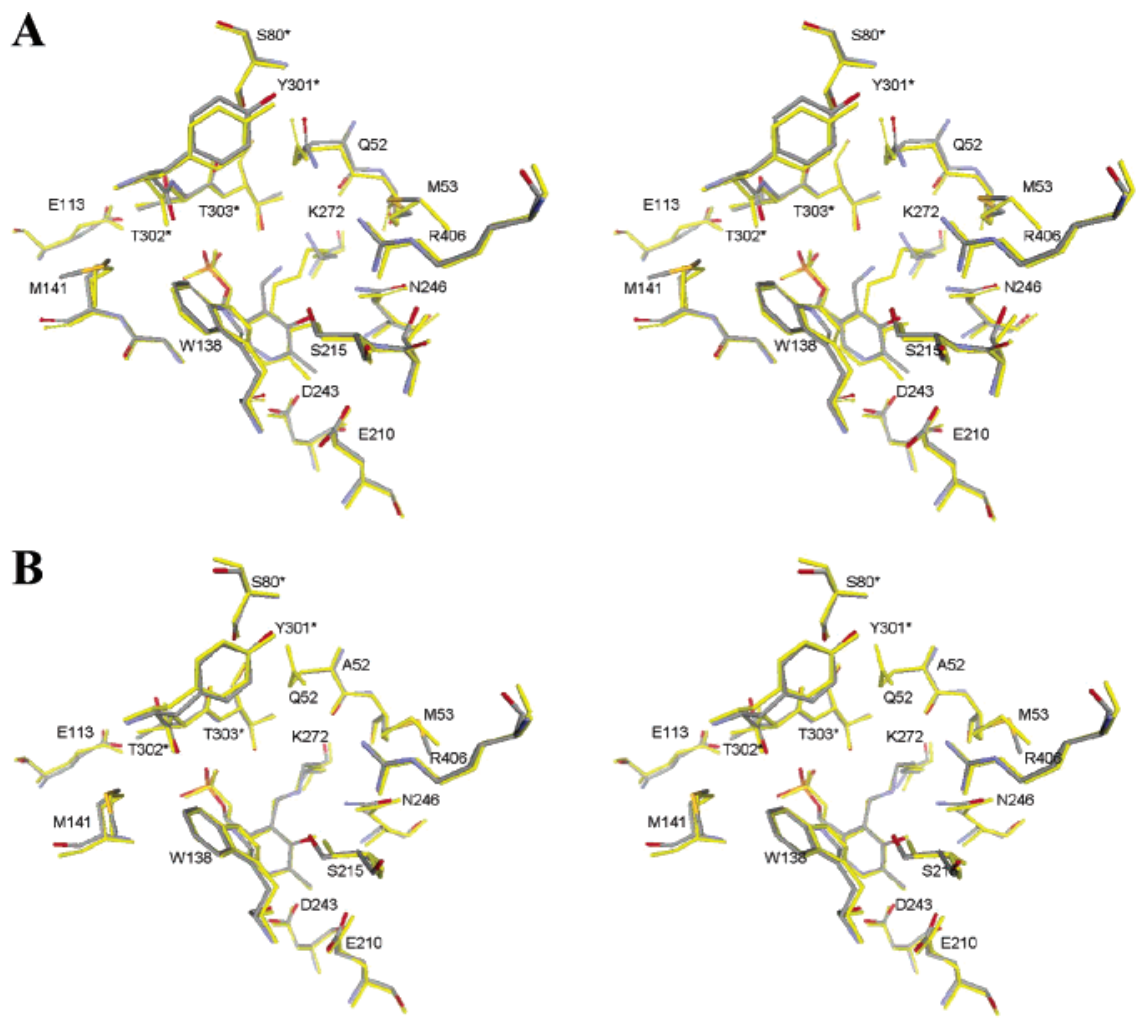

FIGURE 2: (A) Superimposition of the active sites of WT DGD-PLP (yellow) and WT DGD-PMP (CPK). (B) Superimposition of the active sites of WT DGD-PLP (yellow) and Q52A DGD-PLP (CPK). This figure was prepared with Swiss-Pdb Viewer and DS Viewer Pro.

increased approximately 15 -fold, and $K_{\text {pyruvate }}$ has decreased approximately 15 -fold. Steady-state kinetics with the coupled assay were too slow to measure with Q52I or Q52E. These results demonstrate that Q52 is important to efficient catalysis and that the enzyme is highly sensitive to changes at this position.

AIB Decarboxylation Half-Reaction. The AIB decarboxylation half-reaction for Q52A was a complex multiexponential process (Figure 4A). As can be seen from the residuals (inset of Figure 4A), a four-exponential model is not a significantly better fit than the three-exponential model, suggesting an even more complex mechanism.

In Q52I, the spectral changes seen in the AIB decarboxylation half-reaction were well fitted by a serial, two-step model. Global analysis of the absorbance changes yields absorption spectra for the initial, intermediate, and final species for the mechanism, shown in Figure 4B. The concentration dependence of the apparent rate constants is shown in the inset. The half-reaction kinetic parameters are given in Table 3 . The shift from $\sim 410$ to $\sim 420 \mathrm{~nm}$ seen in the first process is consistent with external aldimine formation (20). The linear dependence of the apparent rate constants on substrate concentration, however, suggests that this process is more likely to be the formation of the Michaelis complex. The second-order rate constant for this process is $0.045 \pm 0.003 \mathrm{M}^{-1} \mathrm{~s}^{-1}$. The decrease in $\sim 420$ $\mathrm{nm}$ absorbance and the increase in $\sim 330 \mathrm{~nm}$ absorbance seen in the second process are expected for the conversion of DGD-PLP to DGD-PMP that occurs with oxidative decarboxylation. The apparent rate constants for this process exhibit a hyperbolic dependence on the substrate concentration and were fitted to eq 1 . This yielded a $k_{\text {decarboxylation of }}$ $(6.1 \pm 0.4) \times 10^{-5} \mathrm{~s}^{-1}$ and a $K_{\text {app }}$ of $60 \pm 10 \mathrm{mM}$. Thus,
Q52I shows a decrease in the rate of decarboxylation of $\sim 10^{5}$-fold compared to that of WT. In addition, Michaelis complex formation and/or transimination appears to have been severely affected in the Q52I enzyme.

The spectral changes seen in the AIB decarboxylation halfreaction in Q52E fit well to a serial, two-step model. Global analysis of the absorbance changes yielded the absorption spectra in Figure 5A for the initial, intermediate, and final species. The concentration dependence of the apparent rate constants is shown in the inset, and the kinetic parameters are given in Table 3. The first process corresponds to a decrease in absorbance at $\sim 420 \mathrm{~nm}$ and a slight increase at $\sim 330 \mathrm{~nm}$. On the basis of the spectral changes alone, it is not possible to assign unambiguously this process to a specific chemical step. The $k_{\text {app }}$ is independent of substrate concentration at the substrate concentrations that were used. It was not possible to use less than $300 \mathrm{mM} \mathrm{AIB}$; at lower concentrations, the reaction was too slow to monitor. If the apparent rate constants are averaged, the maximal rate constant $\left(k_{1}\right)$ can be estimated to be $(6.5 \pm 0.8) \times 10^{-3} \mathrm{~s}^{-1}$. The second process shows an absorbance decrease at $\sim 420$ $\mathrm{nm}$ and an increase at $\sim 330 \mathrm{~nm}$ that corresponds to the formation of DGD-PMP. As observed in the first process, $k_{\text {app }}$ is independent of substrate concentration at the substrate concentrations that were used. The maximal rate constant for decarboxylation is estimated to be $(6 \pm 1) \times 10^{-4} \mathrm{~s}^{-1}$ from these data.

The first process seen in Q52E AIB decarboxylation cannot be unambiguously defined on the basis of the spectral changes alone. It could represent reaction of a fast form of the enzyme to produce PMP or another process prior to decarboxylation. To determine whether the first process was formation of PMP from a fast enzyme form, a time course 

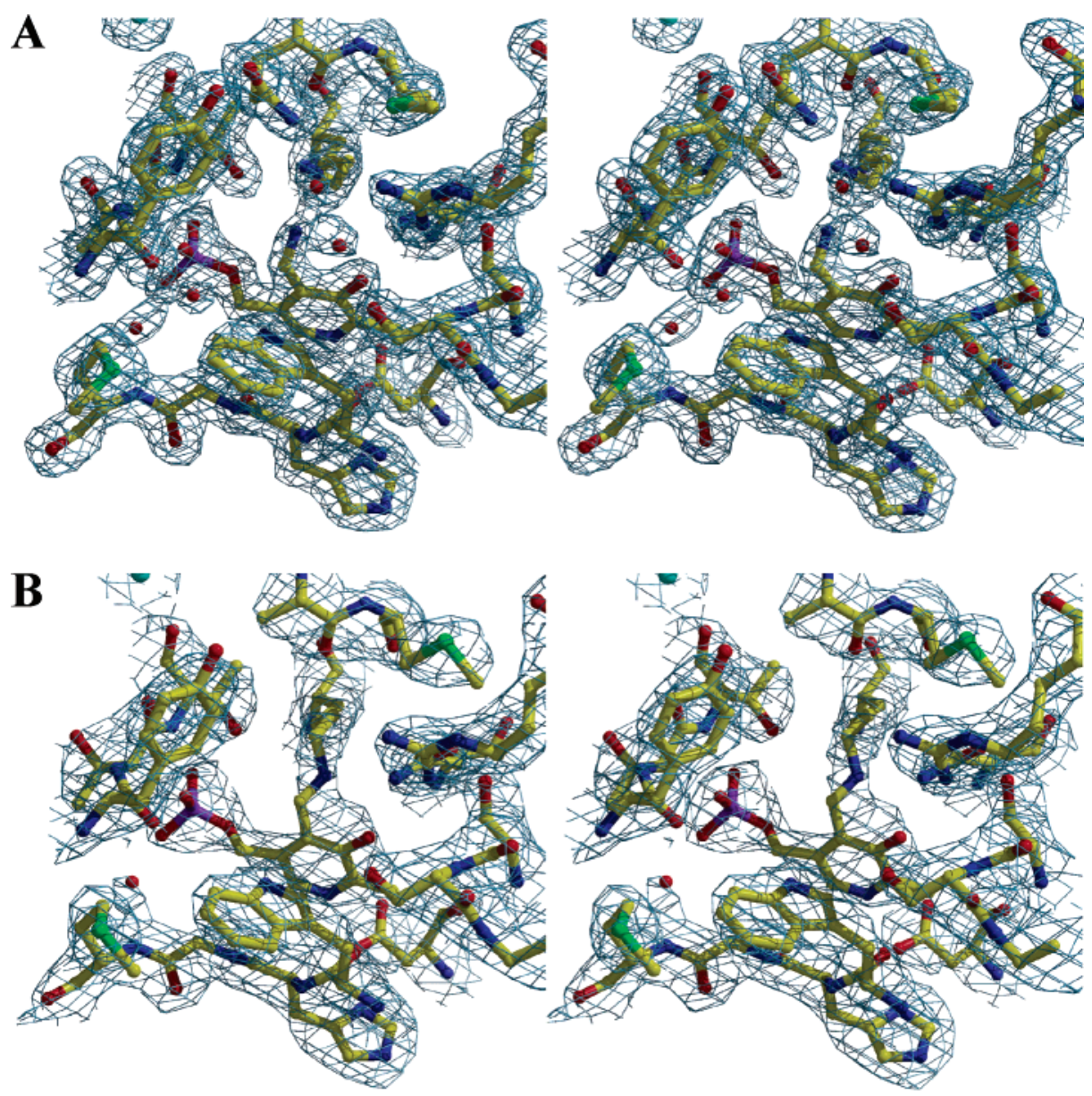

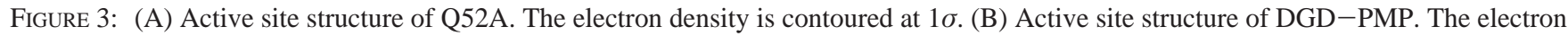
density is contoured at 1.2 $\sigma$. This figure was prepared with BOBSCRIPT.

Table 2: Steady-State Parameters for Q52A and WT DGD ${ }^{a}$

\begin{tabular}{lcccc}
\hline & $k_{\text {cat }}\left(\mathrm{s}^{-1}\right)$ & $K_{\text {AIB }}(\mathrm{mM})$ & $K_{\text {pyr }}(\mu \mathrm{M})$ & $k_{\text {cat }} / K_{\text {AIB }}\left(\mathrm{M}^{-1} \mathrm{~s}^{-1}\right)$ \\
\hline $\mathrm{Q}^{2 \mathrm{~A}}$ & $0.12(0.2)$ & $30(6)$ & $15(3)$ & $3.9(0.2)$ \\
$\mathrm{WT}^{b}$ & $10.4(0.2)$ & $2.0(0.2)$ & $200(2)$ & $5.2(0.1) \times 10^{3}$ \\
\hline
\end{tabular}

${ }^{a}$ Errors are given in parentheses. ${ }^{b}$ All WT data taken from ref 33 .

for PMP formation was performed. The experimental data are shown in Figure 5B along with the corresonding values calculated from $k_{1}$ and $k_{2}$ found spectrally. There is good agreement between the experimental PMP concentrations and the calculated ones assuming only $k_{2}$ corresponds to PMP formation. The experimental data clearly do not agree with the calculated PMP formation assuming both $k_{1}$ and $k_{2}$ correspond to PMP formation. Thus, the first process is not PMP formation from a fast form of the enzyme. The imine nitrogen-protonated ketoenamine form of PLP absorbs at 420 $\mathrm{nm}$, while the phenolic oxygen-protonated enolimine absorbs

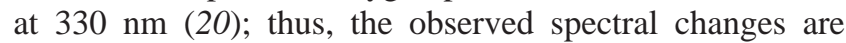
consistent with a shift in the ratio of PLP tautomers. The second process observed is PMP formation where $k_{2}=$ $k_{\text {decarboxylation }}$ Thus, the rate of decarboxylation in Q52E is decreased $>10^{4}$-fold relative to that in WT.

L-Alanine Transamination Half-Reaction. The L-alanine transamination half-reaction was a single-exponential process in Q52A. The decrease in absorbance at $\sim 420 \mathrm{~nm}$ and the increase at $\sim 330 \mathrm{~nm}$ are expected for conversion of DGDPLP to DGD-PMP. The apparent rate constants show a hyperbolic dependence on L-alanine concentration (Figure
6A), giving a $k_{\max }$ of $(2.54 \pm 0.03) \times 10^{-3} \mathrm{~s}^{-1}$ and a $K_{\text {app }}$ of $1.5 \pm 0.1 \mathrm{mM}$. The spectral changes associated with this process suggest that $k_{\max }$ corresponds to formation of PMP. Assuming deprotonation is rate limiting, $k_{\max }=k_{\text {deprot }}$. Comparison of this value to the WT value shows that the rate of L-alanine transamination has decreased approximately 8700-fold in Q52A.

In Q52I, the spectral changes observed in the L-alanine transamination half-reaction fit well to a serial, two-step model. The spectra of the initial, intermediate, and final species obtained from global analysis of the spectral changes are shown in Figure 7A. The concentration dependences of the observed rate constants for the two processes are shown in the inset, and the kinetic parameters are given in Table 4. In the first process, the $\sim 410 \mathrm{~nm}$ peak shifts to $\sim 420 \mathrm{~nm}$ and increases in intensity. Fitting gives a maximal rate constant $k_{1}$ of $(3.28 \pm 0.02) \times 10^{-2} \mathrm{~s}^{-1}$ and a $K_{\text {app }}$ of $50 \pm$ $13 \mathrm{mM}$. The observed spectral changes are consistent with formation of the external aldimine. In the second process, the $\sim 420 \mathrm{~nm}$ peak decays and the magnitude of the $\sim 330$ $\mathrm{nm}$ peak increases which is indicative of PMP formation resulting from transamination. Assuming that deprotonation is rate-limiting, fitting gives a $k_{\text {deprot }}$ of $(3.0 \pm 0.6) \times 10^{-4}$ $\mathrm{s}^{-1}$ and a $K_{\text {app }}$ deprot of $60 \pm 57 \mathrm{mM}$. The rate of L-alanine transamination in Q52I is $\sim 70000$-fold slower than that in WT.

The L-alanine transamination half-reaction in Q52E is not affected to the degree seen in the Q52A and Q52I mutants. 

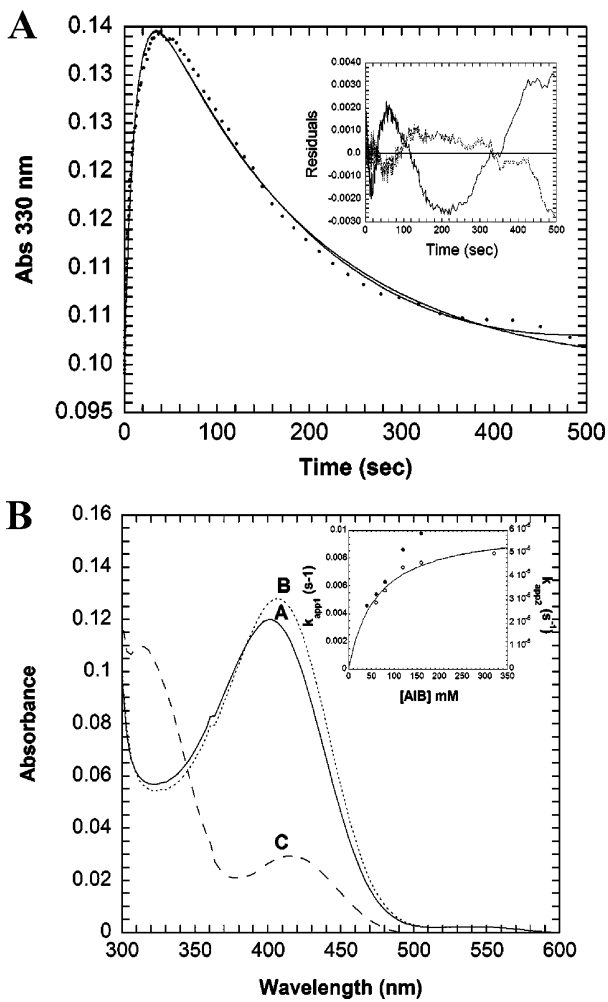

FIGURE 4: (A) Plot of the absorbance at $330 \mathrm{~nm}$ vs time for the AIB decarboxylation half-reaction in Q52A, showing $20 \%$ of the data collected. The lines represent fits to a two- or three-exponential equation. The inset shows the residuals after fitting to a twoexponential (solid line), three-exponential (large dashed line), or four-exponential (small dashed line) model. Experimental conditions: $20 \mu \mathrm{M}$ enzyme, $80 \mathrm{mM}$ AIB, $50 \mathrm{mM}$ TEA-succinate $(\mathrm{pH}$ 7.8), $50 \mathrm{mM}$ dipotassium succinate, and $20 \mu \mathrm{M}$ PLP at $25^{\circ} \mathrm{C}$. (B) Absorbance spectra for the three species in a serial, two-step mechanism obtained from the analysis of multiwavelength data collected in the AIB decarboxylation half-reaction for Q52I. The inset shows the concentration dependence of the observed rate constants $\left[k_{\mathrm{app} 1}(\mathbf{O})\right.$ and $\left.k_{\mathrm{app} 2}(\mathrm{O})\right]$. Experimental conditions: 20 $\mu \mathrm{M}$ enzyme, $80 \mathrm{mM}$ AIB, $50 \mathrm{mM}$ TEA-succinate ( $\mathrm{pH} 7.8), 50 \mathrm{mM}$ dipotassium succinate, and $20 \mu \mathrm{M}$ PLP at $25{ }^{\circ} \mathrm{C}$.

Table 3: AIB Decarboxylation Half-Reaction Kinetic Parameters ${ }^{a}$

\begin{tabular}{llll}
\hline & $k_{\text {bimolecuar }}\left(\mathrm{M}^{-1} \mathrm{~s}^{-1}\right)^{b}$ & \multicolumn{1}{c}{$k_{1}\left(\mathrm{~s}^{-1}\right)^{c}$} & $k_{\text {decarboxylation }}\left(\mathrm{s}^{-1}\right)$ \\
\hline Q52I & $0.045(0.003)$ & $\mathrm{na}^{d}$ & $6.1(0.4) \times 10^{-5}$ \\
Q52E & $\mathrm{na}^{d}$ & $6.5(0.8) \times 10^{-3}$ & $6(1) \times 10^{-4}$ \\
WT & $\mathrm{na}^{d}$ & $\mathrm{na}^{d}$ & $24.5(0.3)^{e}$ \\
\hline
\end{tabular}

${ }^{a}$ The rate constants are the maximal values determined from the global analysis of multiwavelength data. Errors are given in parentheses. ${ }^{b} k_{\text {bimolecuar }}$ is the second-order rate constant for Michaelis complex formation between Q52I-DGD and AIB, determined by spectral changes and the concentration dependence of the rate constant. ${ }^{c} k_{1}$ corresponds to a shift in the ratio of PLP tautomers, determined by spectral changes and PMP quantitation using HPLC. ${ }^{d}$ Not applicable ${ }^{e}$ Data taken from ref 15 .

The spectral changes observed with L-alanine transamination in Q52E fit well to a serial, two-step model. The spectra of the initial, intermediate, and final species obtained from global analysis are shown in Figure 8A, and the inset shows the concentration dependence of the apparent rate constants. In the first process, a peak at $\sim 490 \mathrm{~nm}$, characteristic of the quinonoid intermediate (21), develops while there is a slight decrease in absorbance at $\sim 420 \mathrm{~nm}$. In the second process, the $\sim 490 \mathrm{~nm}$ peak decays and there is a decrease in absorbance at $\sim 420 \mathrm{~nm}$, while absorbance at $\sim 330 \mathrm{~nm}$
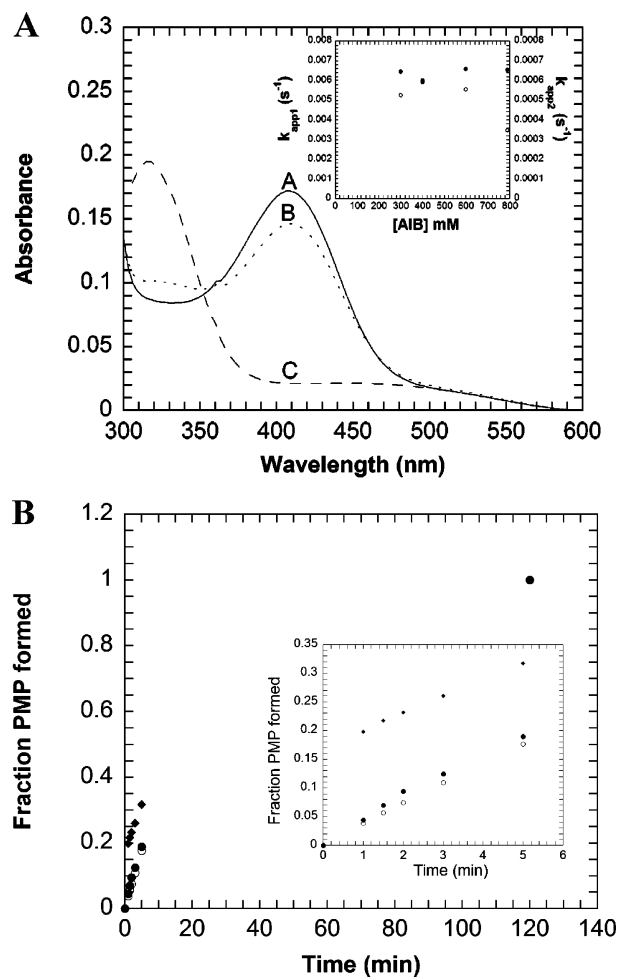

FIGURE 5: (A) Absorbance spectra for the three species in a serial, two-step mechanism obtained from the analysis of multiwavelength data collected for the AIB decarboxylation half-reaction with Q52E. The inset shows the concentration dependence of the rate constants [ $k_{\text {app } 1}(O)$ and $k_{\text {app2 }}(O)$ ]. Below $300 \mathrm{mM}$ AIB the reaction was too slow to characterize. Experimental conditions: $20 \mu \mathrm{M}$ enzyme, 50 $\mathrm{mM}$ TEA-succinate, $50 \mathrm{mM}$ dipotassium succinate, and $20 \mu \mathrm{M}$ PLP at $25^{\circ} \mathrm{C}$. (B) Time course for the formation of PMP in the AIB decarboxylation half-reaction with Q52E, determined by HPLC detection of PMP formation: experimental data ( ), calculated PMP formation assuming only $k_{2}$ corresponds to PMP formation $(\mathrm{O})$, and calculated PMP formation assuming $k_{1}$ and $k_{2}$ correspond to PMP formation $(\checkmark)$. (It was assumed that $17 \%$ of the total enzyme is in the fast form and $83 \%$ in the slow form, based on the amplitude of the observed absorbance change.) The inset shows an expanded view to 0-6 min. Experimental conditions: $20 \mu \mathrm{M}$ enzyme, 600 $\mathrm{mM}$ AIB, $50 \mathrm{mM}$ TEA-succinate, $50 \mathrm{mM}$ dipotassium succinate, and $20 \mu \mathrm{M}$ PLP at $25^{\circ} \mathrm{C}$.

increases. The spectral changes associated with the second process are consistent with reprotonation of the quinonoid to form PMP and pyruvate. The apparent rate constants are linearly dependent on substrate concentration up to $600 \mathrm{mM}$ $\mathrm{L}$-alanine, indicating that $\mathrm{L}$-alanine binding has been greatly impaired in Q52E. The lower limits for the apparent rate constants are given in Table $4\left(k_{\text {deprot }}>20 \mathrm{~s}^{-1}, k_{\text {prot }}>0.3\right.$ $\mathrm{s}^{-1}$ ). In WT, the formation of the quinonoid intermediate in the reaction with L-alanine occurs within the dead time of the stopped-flow instrument and the maximal rate constant for the reprotonation of the quinonoid is $22 \pm 1 \mathrm{~s}^{-1}$ (22). In Q52E, there has been an at most $\sim 70$-fold decrease in the rate of reprotonation relative to that of WT even at a subsaturating concentration of L-alanine.

Pyruvate Transamination Half-Reaction. The pyruvate transamination half-reaction in Q52A displays a burst of activity followed by a steady-state rate (Figure 6B). Equation 2 accounts well for the data. The reaction scheme proposed to account for this result is given in Scheme 2. The observed burst is reaction between DGD-PMP and pyruvate. Thus, $k_{\text {burst }}$ is the rate of transamination. Assuming that deproto- 

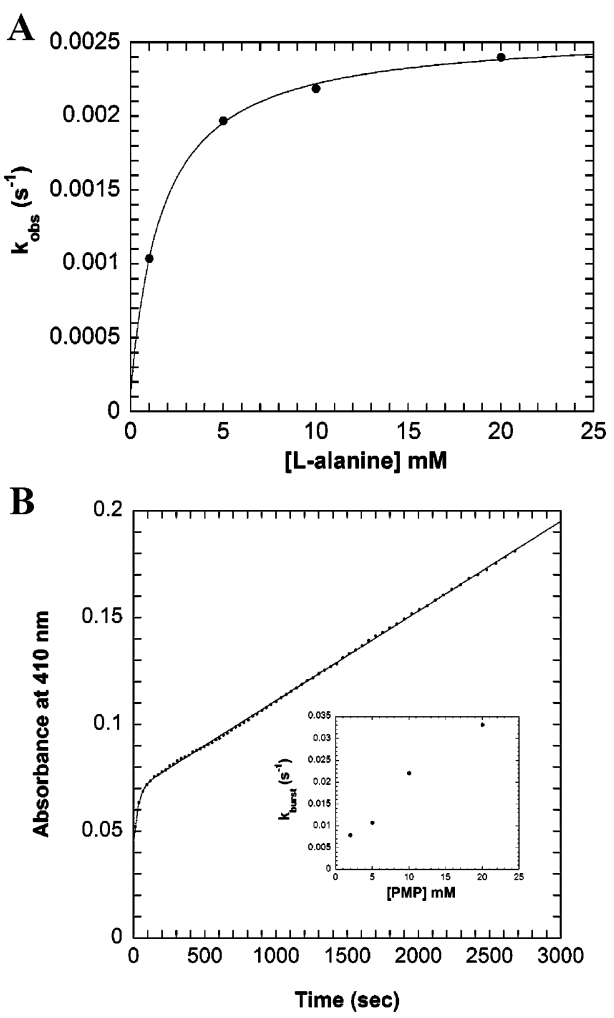

FIGURE 6: (A) Concentration dependence of the observed rate constants for L-alanine transamination in Q52A obtained from analysis of multiwavelength data, where the line represents the fit to eq 1. Experimental conditions: $20 \mu \mathrm{M}$ enzyme, $50 \mathrm{mM}$ TEAsuccinate (pH 7.8), $50 \mathrm{mM}$ dipotassium succinate, and $10 \mu \mathrm{M}$ PLP. (B) Absorbance trace at $410 \mathrm{~nm}$ for Q52A pyruvate transamination corrected for nonenzymatic transamination between PMP and pyruvate, where the line represents the fit to the burst equation (eq 2 ). The inset shows the dependence of $k_{\text {burst }}$ on PMP concentration. Experimental conditions: $20 \mu \mathrm{M}$ enzyme, $100 \mathrm{mM}$ pyruvate, 20 $\mathrm{mM}$ PMP, $50 \mathrm{mM}$ TEA-succinate ( $\mathrm{pH} 7.8$ ), and $50 \mathrm{mM}$ dipotassium succinate at $25^{\circ} \mathrm{C}$.

nation at $\mathrm{C} 4^{\prime}$ of the ketimine intermediate is rate-limiting, $k_{\text {burst }}=k_{\text {deprot }}$. The rate of the steady state could be determined by either release of PLP from the enzyme or binding of PMP to the enzyme. The steady-state $k_{\text {cat }}$ is linearly dependent on PMP concentration (data not shown), suggesting that PMP binding is at least partially rate-limiting. The observed dependence of $k_{\text {burst }}$ on PMP concentration (inset of Figure $6 \mathrm{~B}$ ) shows that even at $20 \mathrm{mM}$ PMP, Q52A is not saturated with cofactor. These data give the following lower limits: $K_{\mathrm{PMP}}>20 \mathrm{mM}$ and $k_{\text {deprot }}>0.04 \mathrm{~s}^{-1}$. The $K_{\mathrm{PMP}}$ in Q52A is at least 30-fold higher than that of WT, indicating that PMP binding has been strongly affected in this mutant. The rate of pyruvate transamination is less affected than that for L-alanine; the extent of pyruvate transamination in Q52A has decreased $\sim 1900$-fold relative to that of WT, while the rate of the L-alanine transamination half-reaction has decreased 8700 -fold in this mutant.

The behavior of the pyruvate transamination half-reaction in Q52I is similar to that observed for Q52A. There is a burst of activity followed by a steady-state rate (Figure 7B), for which eq 2 accounts well. Q52I is not saturated with PMP at $45 \mathrm{mM}$, as seen by the linear dependence of $k_{\text {burst }}$ on PMP concentration (inset of Figure 7B). PMP binding has been greatly affected in this mutant as well, and $K_{\mathrm{PMP}}$ for Q52I is at least 75-fold larger than that of WT. The lower
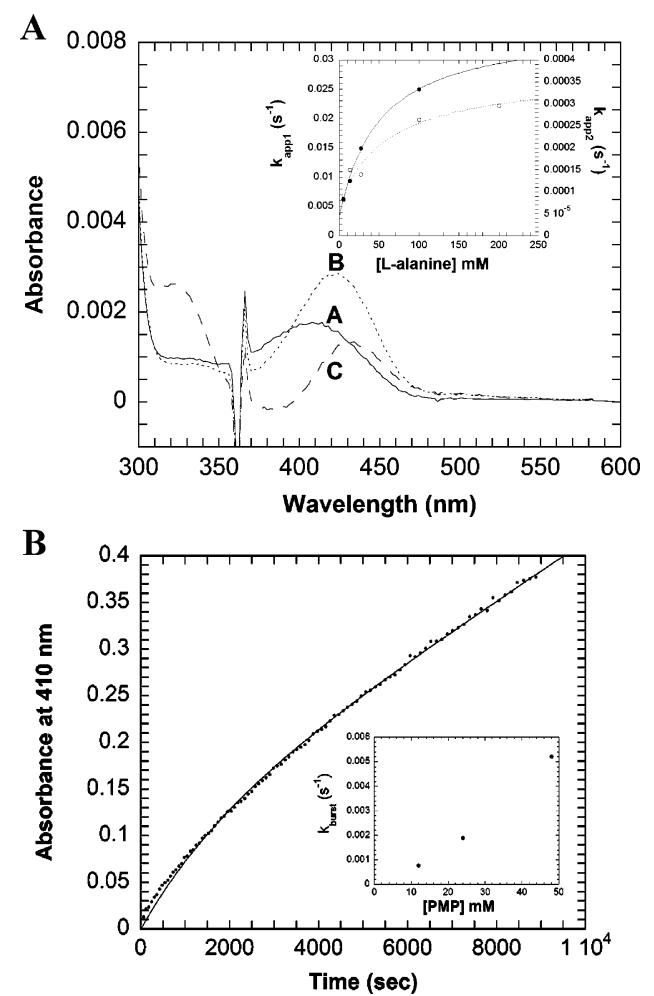

FIGURE 7: (A) Absorbance spectra for the three species in a serial, two-step mechanism obtained from the analysis of multiwavelength data collected in the L-alanine transamination half-reaction for Q52I. The inset shows the concentration dependence of the observed rate constants $\left[k_{\mathrm{app} 1}(\bigcirc)\right.$ and $\left.k_{\mathrm{app} 2}(\mathrm{O})\right]$ fit to eq 1 . Experimental conditions: $20 \mu \mathrm{M}$ enzyme, $13 \mathrm{mM}$ L-alanine, $50 \mathrm{mM}$ TEAsuccinate ( $\mathrm{pH} 7.8$ ), $50 \mathrm{mM}$ dipotassium succinate, and $20 \mu \mathrm{M}$ PLP at $25{ }^{\circ} \mathrm{C}$. (B) Absorbance trace at $410 \mathrm{~nm}$ for Q52I pyruvate transamination corrected for nonenzymatic transamination between PMP and pyruvate, where the line represents the fit to the burst equation (eq 2). The inset shows the dependence of $k_{\text {burst }}$ on PMP concentration. Experimental conditions: $20 \mu \mathrm{M}$ enzyme, $100 \mathrm{mM}$ pyruvate, $12 \mathrm{mM}$ PMP, $50 \mathrm{mM}$ TEA-succinate ( $\mathrm{pH} 7.8$ ), and 50 $\mathrm{mM}$ dipotassium succinate at $25^{\circ} \mathrm{C}$.

limit for the pyruvate transamination rate constant for Q52I $\left(k_{\text {deprot }}\right)$, assuming deprotonation is rate-limiting, is greater than $0.01 \mathrm{~s}^{-1}$. As seen in Q52A, pyruvate transamination is not affected to the same degree as transamination of L-alanine. The rate of pyruvate transamination in Q52I has decreased $\sim 7500$-fold compared to that of WT, while the rate for L-alanine transamination decreased $\sim 70000$-fold for this mutant.

Although PMP binding and the rate of the pyruvate transamination half-reaction are greatly affected in Q52A and Q52I, Q52E has near-WT pyruvate transamination activity and PMP binding, although substrate binding has been greatly affected in this mutant. The spectral changes associated with the pyruvate transamination half-reaction fit well to a serial, two-step model. Global analysis from 375 to $600 \mathrm{~nm}$ gives spectra for the initial, intermediate, and final species (Figure 8B). The dependence of the apparent rate constants on pyruvate concentration is shown in the inset, and the lower limits for $k_{\text {deprot }}$ and $k_{\text {prot }}$ are given in Table 4. As seen for the L-alanine transamination half-reaction in Q52E, the first process is quinonoid formation with a characteristic peak developing at $\sim 490 \mathrm{~nm}$. In the second process, the $\sim 490$ $\mathrm{nm}$ peak decays and the absorbance of the $\sim 420 \mathrm{~nm}$ peak increases, which is consistent with reprotonation of the 
Table 4: Transamination Half-Reaction Kinetic Parameters ${ }^{a}$

\begin{tabular}{|c|c|c|c|c|c|c|c|c|c|c|c|}
\hline & \multicolumn{6}{|c|}{ L-alanine } & \multicolumn{5}{|c|}{ pyruvate } \\
\hline & $\begin{array}{c}k_{\mathrm{EA}} \\
\left(\mathrm{s}^{-1}\right)\end{array}$ & $\begin{array}{l}K_{\text {app }}{ }^{\mathrm{EA}} \\
(\mathrm{mM})\end{array}$ & $\begin{array}{l}k_{\text {deprot }} \\
\left(\mathrm{s}^{-1}\right)\end{array}$ & $\begin{array}{c}K_{\text {app }}{ }^{\text {deprot }} \\
(\mathrm{mM})\end{array}$ & $\begin{array}{l}k_{\text {prot }} \\
\left(\mathrm{s}^{-1}\right)\end{array}$ & $\begin{array}{c}K_{\text {app }}^{\text {prot }} \\
(\mathrm{mM})\end{array}$ & $\begin{array}{l}k_{\text {deprot }} \\
\left(\mathrm{s}^{-1}\right)\end{array}$ & $\begin{array}{c}K_{\text {app }}{ }^{\text {deprot }} \\
(\mathrm{mM})\end{array}$ & $\begin{array}{l}k_{\text {prot }} \\
\left(\mathrm{s}^{-1}\right)\end{array}$ & $\begin{array}{c}K_{\text {app prot }}^{\text {pro }} \\
(\mathrm{mM})\end{array}$ & $k_{\mathrm{f}} / k_{\mathrm{r}}$ \\
\hline Q52A & & & $2.54(0.03) \times 10^{-3 b}$ & $1.5(0.1)$ & & & $>0.04^{b}$ & & & & $>16$ \\
\hline Q52I & $3.28(0.02) \times 10^{-2}$ & $50(13)$ & $3.0(0.6) \times 10^{-4}$ & $60(57)$ & & & $>0.01^{b}$ & & & & $>30$ \\
\hline Q52E & & & $>20$ & $>600$ & $>0.3$ & $>600$ & $>30$ & $>400$ & $>12$ & $>400$ & \\
\hline WT & & & & & $23.6^{c}(0.7)$ & $6.6^{c}(0.7)$ & & & $75^{c}(2)$ & $1.1^{c}(0.1)$ & 3 \\
\hline
\end{tabular}

${ }^{a}$ The rate constants are the maximal values for WT L-alanine and pyruvate, Q52A L-alanine, and Q52I L-alanine transamination. The values for Q52E were determined at $600 \mathrm{mM}$ L-alanine and $400 \mathrm{mM}$ pyruvate and are lower limits. The $k_{\text {deprot }}$ values for pyruvate transamination in Q52A and Q52I are lower limits determined at 20 and $45 \mathrm{mM} \mathrm{PMP}$, respectively. $k_{\mathrm{EA}}$ and $K_{\mathrm{EA}}$ refer to the rate constant and apparent dissociation constant for the formation of the external aldimine, respectively. $k_{\text {deprot }}$ and $K_{\text {deprot }}$ refer to the deprotonation of the external aldimine to form the quinonoid intermediate. $k_{\text {prot }}$ and $K_{\text {prot }}$ refer to protonation of the quinonoid intermediate. Errors are given in parentheses. ${ }^{b}$ It is assumed that the slowest step in the transamination half-reaction is deprotonation of the external aldimine. ${ }^{c}$ Data taken from ref 34.

A
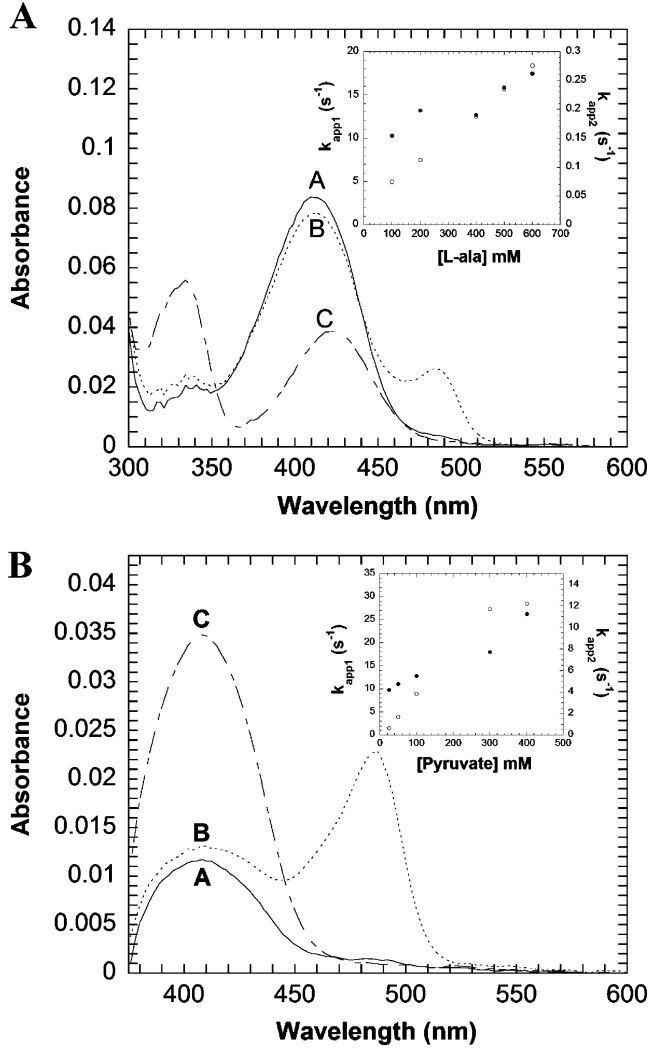

FIGURE 8: (A) Absorbance spectra for the three species in a serial, two-step mechanism obtained from the analysis of multiwavelngth data collected in the L-alanine transamination half-reaction for Q52E. The inset shows the concentration dependence of the observed rate constants $\left[k_{\text {app1 }}(\bullet)\right.$ and $k_{\text {app2 }}(\mathrm{O})$ ]. Experimental conditions: $20 \mu \mathrm{M}$ enzyme, $400 \mathrm{mM}$ L-alanine, $50 \mathrm{mM}$ TEAsuccinate, $50 \mathrm{mM}$ dipotassium succinate, and $20 \mu \mathrm{M}$ PLP at 25 ${ }^{\circ} \mathrm{C}$. (B) Absorbance spectra for the three species in a serial, twostep mechanism obtained from the analysis of multiwavelength data collected in the pyruvate transamination half-reaction for Q52E. The inset shows concentration dependence of the observed rate constants $\left[k_{\text {app1 }}(\bigcirc)\right.$ and $\left.k_{\text {app2 }}(\bigcirc)\right]$. Experimental conditions: 10 $\mu \mathrm{M}$ enzyme, $1 \mathrm{mM}$ PMP, $50 \mathrm{mM}$ TEA-succinate, and $50 \mathrm{mM}$ dipotassium succinate at $25^{\circ} \mathrm{C}$.

quinonoid to form PLP and L-alanine. The spectral changes at $\sim 330 \mathrm{~nm}$ cannot be monitored in this case, as free PMP absorbs in this range and obscures the expected decrease at $330 \mathrm{~nm}$ that occurs due to conversion of DGD-PMP to DGD-PLP. Pyruvate binding has been greatly affected in Q52E; the apparent rate constants for both processes are linearly dependent on pyruvate concentration even up to 400 $\mathrm{mM}$ pyruvate. A lower limit for deprotonation of the ketimine
Scheme 2

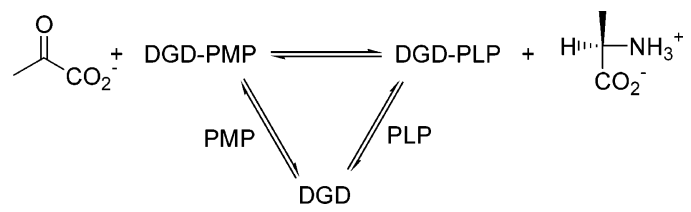

to form the quinonoid intermediate $\left(k_{\text {deprot }}\right)$ is greater than $30 \mathrm{~s}^{-1}$, and the rate of reprotonation of the quinonoid to form $\operatorname{PLP}\left(k_{\text {prot }}\right)$ is greater than $12 \mathrm{~s}^{-1}$. Comparison of $k_{\text {prot }}$ in Q52E to the rate for the same process in WT shows that at most Q52E shows an $\sim 6$-fold decrease in the rate of the pyruvate transamination half-reaction compared to that of WT.

Steady-State Transamination in Q52E. Steady-state transamination using L-alanine and $\alpha$-ketocaproate $(\alpha \mathrm{kc})$ (Figure 9) confirms that binding of L-alanine and binding of $\alpha$-keto acids have been affected $\left(K_{\mathrm{\alpha kc}}>450 \mathrm{mM}\right)$ at $600 \mathrm{mM}$ L-alanine. The lower limit for the steady-state rate of transamination $\left(k_{\text {cat }}\right)$ is greater than $5.5 \times 10^{-3} \mathrm{~s}^{-1}$, showing an at most $\sim 100$-fold decrease in activity relative to that of WT.

\section{DISCUSSION}

Dunathan (2) proposed that PLP dependent enzymes use stereoelectronic effects to control reaction specificity. DGD provides an excellent system in which to study these effects due to the differential binding requirements necessary for the unusual dual reaction specificity of the enzyme. As previous work has shown, DGD has two carboxylate binding

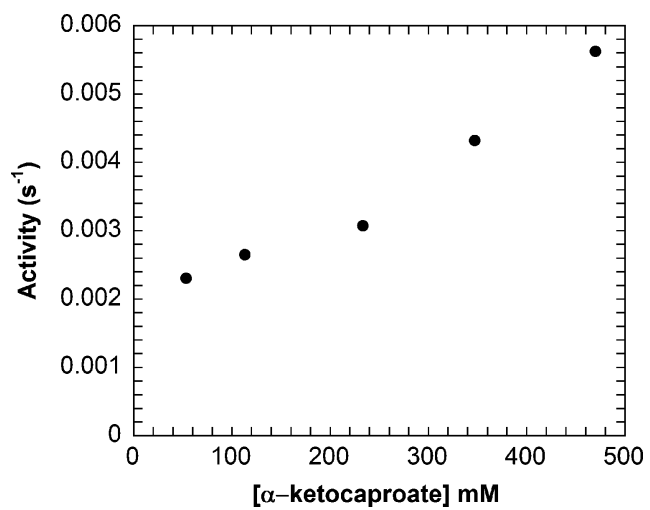

FIGURE 9: Q52E saturation curve for steady-state transamination with L-alanine and $\alpha$-ketocaproate. Experimental conditions: 500 $\mathrm{mM}$ L-alanine, $33 \mu \mathrm{M}$ enzyme, $67 \mu \mathrm{M}$ PLP, $10 \mathrm{mM} \mathrm{NH}_{4}{ }^{+}$, and 2.8 units $/ \mathrm{mL}$ Ala-DH at $25^{\circ} \mathrm{C}$. The reaction was monitored at 380 $\mathrm{nm}$. 
Scheme 3

$$
\begin{aligned}
\mathrm{AIB}+\mathrm{E} & \stackrel{\mathrm{k}_{1}}{\underset{\mathrm{k}_{2}}{\rightleftharpoons}} \text { E-AIB } \stackrel{\mathrm{k}_{3}}{\longrightarrow} \text { acetone }+\mathrm{CO}_{2}+\mathrm{E}^{\prime} \\
\text { Pyruvate }+\mathrm{E}^{\prime} & \stackrel{\mathrm{k}_{4}}{\underset{\mathrm{k}_{5}}{\rightleftharpoons}} \text { E'-pyr } \stackrel{\mathrm{k}_{6}}{\underset{\mathrm{k}_{7}}{\rightleftharpoons}} \text { L-ala }+\mathrm{E}
\end{aligned}
$$

sites (11). The A subsite (Figure 1) can bind a carboxylate in a position that is stereoelectronically activated for decarboxylation. The B subsite can also bind a carboxylate, but in this position, stereoelectronic effects (i.e., orbital overlap) are not maximized. Therefore, one expects poor activation toward decarboxylation from the B subsite.

Q52 is located in the stereoelectronically activated A subsite, and it has been proposed, on the basis of X-ray crystallographic studies, to hydrogen bond with the substrate carboxylate, thereby helping to keep it in the A subsite (12); Q52 plays no other obvious role in catalysis. To the degree that stereoelectronic effects accelerate the rate of decarboxylation in DGD, mutation of Q52 to amino acids with side chains that no longer stabilize the carboxylate in the A subsite (Q52A) or actively prevent binding of the carboxylate in this subsite (Q52I and Q52E) is predicted to reduce the rate of decarboxylation. In analogy to transamination in aspartate aminotransferase, $\mathrm{K} 272$ is expected to be the critical general base catalyst in the transamination half-reaction and Q52 plays no obvious role in this half-reaction (23). As a result, the Q52 mutants are predicted by simple reasoning on the basis of the functional active site model to have near-WT transamination activity.

Steady-State Kinetics. The steady-state studies (Table 2) demonstrate the importance of Q52 to catalysis. In addition to the decrease in $k_{\text {cat }}$ and the increase in $K_{\text {AIB }}$ expected on the basis of the functional active site model, these studies find that the value for $K_{\text {pyruvate }}$ in Q52A has decreased relative to that of WT. The decrease in the apparent Michaelis constant for pyruvate in Q52A is most likely not due to differential binding in this mutant, since pyruvate binds with the carboxylate in the B subsite, removed from the Q52A mutation. Instead, the observed decrease is likely a kinetic effect. Michaelis constants for a ping-pong mechanism (Scheme 3) are aggregates of microscopic rate constants (24).

$$
K_{\text {pyruvate }}=\frac{V_{\mathrm{f}}\left(k_{5}+k_{6}\right)}{k_{4} k_{6}} \text { where } V_{\mathrm{f}}=\frac{k_{3} k_{7}}{k_{3}+k_{7}}
$$

As can be seen from eq 3, the observed Michaelis constant for pyruvate, $K_{\text {pyruvate, }}$ in Q52A may be lower than the WT $K_{\text {pyruvate }}$ if the rate of decarboxylation, $k_{3}$, is significantly slower than the rate of transamination, $k_{7}$, in Q52A. Thus, the observed decrease in $K_{\text {pyruvate }}$ indirectly suggests that the rate of decarboxylation has been affected to a greater degree than the rate of pyruvate transamination in Q52A, consistent with the prediction that Q52 is mechanistically more important in the decarboxylation half-reaction.

Decarboxylation and Transamination Half-Reactions in Q52A and Q52I. Analysis of the AIB decarboxylation halfreactions in Q52A and Q52I show large decreases in the rate of decarboxylation for Q52A and Q52I (Table 3), supporting the prediction that stereoelectronic effects are important to the catalysis of decarboxylation in DGD.

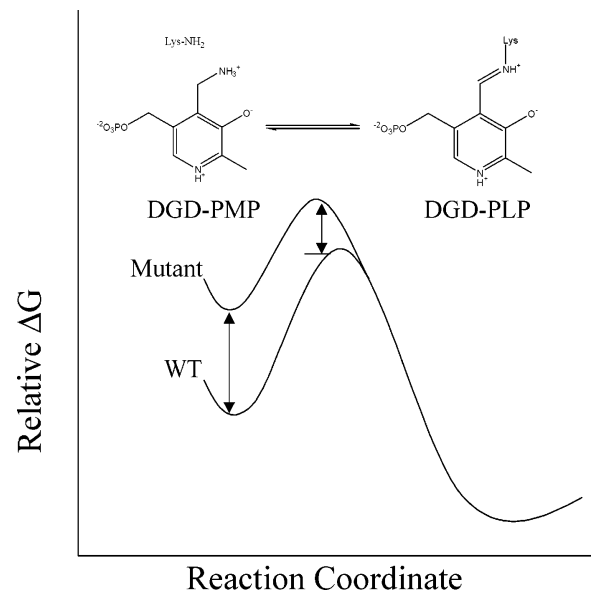

FIGURE 10: Reaction coordinate diagram illustrating selective destabilization of the PMP form of Q52A or Q52I and the effect on the relative energies of the trasition states for WT and the Q52A or Q52I mutant.

Unexpectedly, the rate of L-alanine transamination in both mutants has decreased significantly (Table 4). The decrease in the rate of both the AIB decarboxylation and the L-alanine transamination half-reactions suggests that the Q52A and Q52I mutations have unforeseen pleiotropic effects. Since Q52 plays no obvious catalytic role in transamination, one possible explanation is that the Q52 residue may be structurally important. However, it is unlikely that either Q52A or Q52I lacks activity due to major structural differences from WT, since the X-ray crystallographic structure of Q52A is essentially identical to that of WT except for the site of mutation (Figure 2B).

Another explanation for the slow L-alanine transamination observed in Q52A and Q52I is that the PMP form of the enzyme is selectively destabilized in these mutants due to the loss of an undetermined interaction between the side chain amide of Q52 and PMP (Figure 10). If the energy of DGD-PMP is higher in these mutants than in WT, while the energy of DGD-PLP remains roughly unperturbed, one predicts that the rate of reactions converting DGD-PLP to DGD-PMP (e.g., AIB decarboxylation and L-alanine transamination) will be slowed selectively. The testable prediction from this hypothesis is that, relative to $\mathrm{L}$-alanine transamination, the rate of pyruvate transamination will be increased in the mutants to a greater degree than in WT. This prediction is borne out for Q52A and Q52I by studies of the pyruvate transamination half-reaction (Table 4).

Further support for the selective destabilization of the PMP form in Q52A and Q52I comes from measurement of dissociation constants for PMP and PLP in these mutants. The larger increase in $K_{\mathrm{PMP}}$ compared to that in $K_{\mathrm{PLP}}$ in Q52A (Table 5) demonstrates that the energy of DGD-PMP has been increased selectively compared to that of DGD-PLP. These studies show that Q52 plays a role in selectively stabilizing DGD-PMP which was not apparent from the $\mathrm{X}$-ray crystallographic structures $(12,14,25)$.

Structural Origin of Weak PMP Binding in Q52A and Q52I. The Q52A-PLP structure is virtually identical to the WT-PLP structure (Figure 2B). This is not unexpected given that Q52A binds PLP well; it is the PMP form of Q52A that is unstable relative to WT. The Q52A-PMP structure would likely identify the structural origin of the weak PMP binding 


\begin{tabular}{ccl}
\hline \multicolumn{3}{c}{ Table 5: Dissociation Constants for Cofactor Binding } \\
\hline & \multicolumn{1}{c}{$K_{\mathrm{PMP}}(\mathrm{mM})$} & $K_{\mathrm{PLP}}(\mu \mathrm{M})$ \\
\hline Q52A & $>30^{b}$ & $15(3)^{c}$ \\
Q52I & $>50^{b}$ & $\mathrm{nd}^{f}$ \\
Q52E & $0.05(0.01)^{d}$ & $\mathrm{nd}^{f}$ \\
WT & $0.6^{e}$ & $3.7(0.3)^{g}$
\end{tabular}

${ }^{a}$ Errors are given in parentheses. ${ }^{b} K_{\mathrm{PMP}}$ values for Q52A and Q52I were taken from the dependence of $k_{\text {burst }}$ on PMP concentration and are a lower limit as $k_{\text {burst }}$ is linearly dependent on PMP at the concentrations that were used. ${ }^{c} K_{\text {PLP }}$ was determined using the steadystate assay described in Experimental Procedures. ${ }^{d} K_{\mathrm{PMP}}$ for Q52E is taken from the concentration dependence of the apparent rate constants taken from the global analysis of pyruvate transamination at $100 \mathrm{mM}$ pyruvate. ${ }^{e}$ Taken from ref $34 .{ }^{f}$ Not determined. ${ }^{g}$ Taken from ref 33.

in this mutant. However, the high dissociation constant for PMP in Q52A makes this structure inaccessible. The WTPMP structure was determined to provide some insight into the structural origin of weak PMP binding in Q52A and Q52I. This structure (Figure 3) indeed suggests the structural role Q52 may play in PMP binding, showing that Q52 hydrogen bonds to a water molecule that shares a hydrogen bond with the amino group of PMP. In the Q52A and Q52I mutants, this water is unlikely to be present due to the loss of the Q52 hydrogen bond. Although it is surprising that an indirect hydrogen bonding interaction such as this would have such a dramatic effect on the stability of the PMP form of the Q52A and Q52I mutants, it is the only clear interaction between Q52 and PMP and at least contributes to the relative instability of the PMP form of Q52A and Q52I.

Formation of the Michaelis Complex and Formation of the External Aldimine Are Affected in Q52I. Both decarboxylation and L-alanine transamination half-reaction kinetics in Q52I show that this mutation has significantly affected formation of the Michaelis complex and/or transimination (i.e., Schiff base interchange). The effect on Michaelis complex formation and/or transimination is initially surprising considering that GABA-AT, an aminotransferase that is highly homologous to DGD, has an isoleucine residue in this position and is able to catalyze efficiently both formation of the Michaelis complex and formation of the external aldimine (26). An overlay of DGD and the recently determined structure of $E$. coli GABA-AT shows that although the two enzymes are similar, the $\mathrm{C}_{\alpha}$ atoms of Q52 in DGD and the corresponding I50 in GABA-AT are positioned differently, $\sim 2.3 \AA$ apart $(26,27)$. It is likely that this difference in positioning is responsible for differences seen in Michaelis complex formation observed in Q52I DGD and GABA-AT. In addition, models show the Q52I mutation eliminates interactions between the side chain and Y301 and S80 which allows I52 to move into the active site pocket. The greater proximity of the isoleucine side chain to the internal aldimine may sterically prevent efficient formation of the Michaelis complex and/or transimination. The dramatic effect of the Q52I mutation on Michaelis complex formation underscores the importance of subtle positioning to binding and catalysis in DGD and GABA-AT.

Decarboxylation and Transamination in Q52E. The Q52E mutation was designed to eliminate binding of the substrate carboxylate in the activated A subsite due to electrostatic repulsion between the carboxylate of the substrate and the glutamate side chain, thereby inhibiting decarboxylation. As observed with Q52A and Q52I, this prediction is borne out

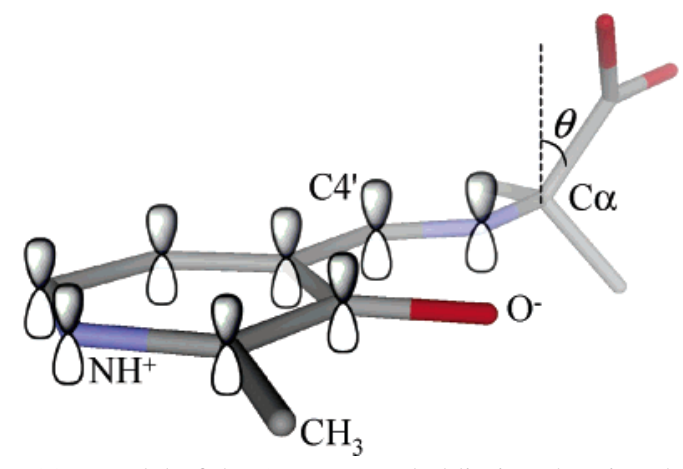

FIGURE 11: Model of the AIB external aldimine showing the angle between the $\pi$ system of the PLP ring and the $\mathrm{C}_{\alpha}-\mathrm{CO}_{2}{ }^{-}$bond $(\theta)$.

by experiment; the extent of decarboxylation in Q52E has decreased approximately $10^{4}$-fold relative to that in WT. Analysis of steady-state and half-reaction transamination in Q52E demonstrates that the mutant, although significantly affected in substrate binding, is still catalytically competent (Table 4). The decrease seen in the rate of AIB decarboxylation is therefore specific to the decarboxylation halfreaction as expected if stereoelectronic effects play a significant role in the decarboxylation half-reaction.

Estimation of Stereoelectronic Effects in DGD. The observed rate of decarboxylation in Q52E can be used to estimate the energetic contribution of stereoelectronic effects to catalysis in DGD. To calculate the true contribution of stereoelectronic effects to catalysis, the rate of decarboxylation from the activated A subsite and the rate of decarboxylation from a nonactivated position are needed. The rate of decarboxylation in Q52E ( $\left.k_{\text {decarboxylation }}=6 \times 10^{-4} \mathrm{~s}^{-1}\right)$ can be used as an estimate of the rate of decarboxylation from the nonactivated position by assuming that the Q52E mutation precludes carboxylate binding at the A subsite. The rate of decarboxylation from the activated A subsite can be estimated using the WT value for the AIB decarboxylation half-reaction and previous studies showing that approximately one-fifth of the substrate binds with the carboxylate in the A subsite (11), allowing the calculation of the rate of decarboxylation from the A subsite $\left(k_{\text {activated }}=125 \mathrm{~s}^{-1}\right)$.

Decarboxylation is a charge neutralization process, and gross changes in the electrostatic environment will cause the relative energies of the ground state and transition state to shift, affecting the rate of reaction. Therefore, it is also necessary to assume that the electrostatic environment of the A subsite in WT and that of the B subsite in Q52E are equivalent. This is a reasonable assumption; although not identical, the interactions of the carboxylate in the A and B subsite are grossly similar.

With these assumptions, the values for $k_{\text {activated }}$ and $k_{\text {nonactivated }}$ and eq 4 give a value for $\Delta G_{\text {stereoelectronic }}$ of -7.3 $\mathrm{kcal} / \mathrm{mol}$.

$$
\Delta G_{\text {stereoelectronic }}=-R T \ln \left(\frac{k_{\text {activated }}}{k_{\text {nonactivated }}}\right)
$$

This value is an estimate that does not take several factors into account. Ideally, the calculation would account for the angular dependence of orbital overlap between the $\pi$ system and the scissile bond (Figure 11). If decarboxylation in WT takes place from a position less than perfectly parallel to the $\pi$ system of the aldimine, the WT rate of decarboxylation 
is not $k_{\text {activated }}$ but is instead $\cos ^{2} \theta \times k_{\text {activated, }}$, where $\theta$ is the angle between the scissile bond and the $\pi$ system (28). This would make the value used here an underestimate of the rate of decarboxylation from the maximally activated position, and therefore of the total possible stereoelectronic activation. Although both semiempirical calculations of decarboxylation in DGD (13) and X-ray crystallographic studies with aminophosphonate inhibitors (12) suggest that decarboxylation may not begin with the $\mathrm{C}_{\alpha}-\mathrm{CO}_{2}{ }^{-}$bond aligned parallel to the $\pi$ system of the aldimine, the contribution of the angular dependence to $\Delta G_{\text {stereoelectronic }}$ is small unless the angle is large. Therefore, small deviations from a parallel orbital alignment as might occur at the A subsite with AIB, although conceptually important, are not considered here.

In calculating the value for stereoelectronic effects in DGD, we assume that decarboxylation in Q52E takes place exclusively from the nonactivated B subsite. It is possible, however, that decarboxylation continues to occur from the activated A subsite from a small fraction of substrate that binds with its carboxylate in this electrostatically unfavorable position. In this case, the rate of decarboxylation from the nonactivated $\mathrm{B}$ subsite would be much slower than the observed rate of decarboxylation in Q52E and the $\Delta G_{\text {stereo- }^{-}}$ electronic calculated above is a lower limit for and poor estimate of the true value. Although this possibility cannot be eliminated, the $\mathrm{pH}$ independence of the AIB decarboxylation half-reaction (data not shown) suggests that the E52 residue is ionized in the DGD active site and weighs strongly against the possibility of substrate carboxylate binding and of decarboxylation occurring from the A subsite.

Stereoelectronic Effects in Perspective. Stereoelectronic effects were first proposed by Corey and Sneen (4) to explain the $\sim 12$-fold faster axial protonation than equatorial protonation in enolization reactions. Other studies have shown that stereoelectronic control governs the abstraction of a proton $\alpha$ to an iminium ion (7) as well. The enolization of acetaldehyde was studied by Houk's group using quantum mechanical methods (6), and the magnitude of stereoelectronic effects in this reaction was calculated to be $9.8 \mathrm{kcal} /$ mol. Stereoelectronic effects in DGD might be expected to be considerably larger than found in these systems due to the possibility of greater electron delocalization into the pyridine ring. However, previous work with decarboxylation in PLP model systems using ab initio calculations (29) and the DGD active site using semiempirical methods (13) suggests that the pyridine ring of PLP is not the major contributor to transition-state stabilization. Instead, the imine/ iminium function may provide the majority of the stabilization. In this case, the experimental value found in this study may be considered to be in reasonably good agreement with the ab initio study.

A careful search of the literature shows no published examples of a PLP dependent enzyme catalyzing the cleavage of more than one bond to $\mathrm{C}_{\alpha}$ with its natural substrate, except DGD which catalyzes both transamination and decarboxylation with L-alanine (11). The found value of $7.3 \mathrm{kcal} / \mathrm{mol}$ corresponds to one side reaction every one in $10^{6}$ turnovers, which is within the detection limits of studies of ornithine decarboxylase (30) and aspartate aminotransferase $(31,32)$ that find no evidence of side reactions which differ in the bond to $\mathrm{C}_{\alpha}$ that is broken. This suggests that the value calculated here for $\Delta G_{\text {stereoelectronic }}$ may be a lower limit due to the limitations inherent to the experimental system. PLP dependent enzymes have additional means at their disposal for maintaining reaction specificity, such as appropriate placement of acid-base catalysts in the active site. Even though PLP dependent enzymes use other means to control reaction specificity, it is physiologically significant that simple alignment of the external aldimine in the enzyme active site accounts for an at least $10^{5}$-fold preference for the cleavage of the activated bond.

\section{REFERENCES}

1. Christen, P., and Metzler, D. E. (1985) Transaminases, Wiley, New York.

2. Dunathan, H. C. (1966) Conformation and reaction specificity in pyridoxal phosphate enzymes, Proc. Natl. Acad. Sci. U.S.A. 55, $712-6$.

3. Kirby, A. J. (1996) Stereoelectronic effects, Oxford University Press, New York.

4. Corey, E. J., and Sneen, R. A. (1956) Stereoelectronic Control in Enolization-Ketonization Reactions, J. Am. Chem. Soc. 78, 626978.

5. Deslongchamps, P. (1983) Stereoelectronic effects in organic chemistry, 1st ed., Pergamon Press, New York.

6. Behnam, S. M., Behnam, S. E., Ando, K., Green, N. S., and Houk, K. N. (2000) Stereoelectronic, torsional, and steric effects on rates of enolization of ketones, J. Org. Chem. 65, 8970-8.

7. Ferran, H. E., Roberts, R. D., Jacob, J. N., and Spencer, T. A. (1978) Stereoelectronic Control of a Proton Abstraction from Iminium ions, J. Chem. Soc., Chem. Commun. 2, 49-50.

8. McPhalen, C. A., Vincent, M. G., and Jansonius, J. N. (1992) $\mathrm{X}$-ray structure refinement and comparison of three forms of mitochondrial aspartate aminotransferase, J. Mol. Biol. 225, 495517.

9. O'Leary, M. H., and Piazza, G. J. (1978) Specificity in enzymatic decarboxylation, J. Am. Chem. Soc. 100, 632-3.

10. Milne, J. J., and Malthouse, J. P. (1996) The effect of different amino acid side chains on the stereospecificity and catalytic efficiency of the tryptophan synthase-catalysed exchange of the $\alpha$-protons of amino acids, Biochem. J. 314 (Part 3), 787-91.

11. Sun, S., Zabinski, R. F., and Toney, M. D. (1998) Reactions of alternate substrates demonstrate stereoelectronic control of reactivity in dialkylglycine decarboxylase, Biochemistry 37, 3865-75.

12. Liu, W., Rogers, C. J., Fisher, A. J., and Toney, M. D. (2002) Aminophosphonate inhibitors of dialkylglycine decarboxylase: Structural basis for slow binding inhibition, Biochemistry 41, $12320-8$

13. Toney, M. D. (2001) Computational studies on nonenzymatic and enzymatic pyridoxal phosphate catalyzed decarboxylations of 2-aminoisobutyrate, Biochemistry 40, 1378-84.

14. Toney, M. D., Hohenester, E., Keller, J. W., and Jansonius, J. N. (1995) Structural and mechanistic analysis of two refined crystal structures of the pyridoxal phosphate-dependent enzyme dialkylglycine decarboxylase, J. Mol. Biol. 245, 151-79.

15. Zhou, X., Kay, S., and Toney, M. D. (1998) Coexisting kinetically distinguishable forms of dialkylglycine decarboxylase engendered by alkali metal ions, Biochemistry 37, 5761-9.

16. Sambrook, J., and Russell, D. W. (2001) Molecular cloning: a laboratory manual, 3rd ed., Cold Spring Harbor Laboratory Press, Plainview, NY.

17. Eichele, G., Ford, G. C., and Jansonius, J. N. (1979) Crystallization of pig mitochondrial aspartate aminotransferase by seeding with crystals of the chicken mitochondrial isoenzyme, J. Mol. Biol. 135, 513-6.

18. Collaborative Computational Project Number 4 (1994) The CCP4 suite: Programs for protein crystallography, Acta Crystallogr. D50, 760-3.

19. Tryfiates, G. P., and Sattsangi, S. (1982) Separation of vitamin $\mathrm{B}_{6}$ compounds by paired-ion high-performance liquid chromatography, J. Chromatogr. 227, 181-6.

20. Metzler, C. M., and Metzler, D. E. (1987) Quantitative description of absorption spectra of a pyridoxal phosphate-dependent enzyme using log-normal distribution curves, Anal. Biochem. 166, $313-$ 27. 
21. Schirch, L., and Slotter, R. A. (1966) Spectral properties of Schiff bases of amino acid esters with pyridoxal and pyridoxal $\mathrm{N}$ methochloride in ethanol, Biochemistry 5, 3175-81.

22. Sun, S., Bagdassarian, C. K., and Toney, M. D. (1998) Pre-steadystate kinetic analysis of the reactions of alternate substrates with dialkylglycine decarboxylase, Biochemistry 37, 3876-85.

23. Toney, M. D., and Kirsch, J. F. (1993) Lysine 258 in aspartate aminotransferase: Enforcer of the Circe effect for amino acid substrates and general-base catalyst for the 1,3-prototropic shift, Biochemistry 32, 1471-9.

24. Velick, S. F., and Vavra, J. (1962) A kinetic and equilibrium analysis of the glutamic oxaloacetate transaminase mechanism, J. Biol. Chem. 237, 2109-22.

25. Malashkevich, V. N., Strop, P., Keller, J. W., Jansonius, J. N., and Toney, M. D. (1999) Crystal structures of dialkylglycine decarboxylase inhibitor complexes, J. Mol. Biol. 294, 193-200.

26. Liu, W., Peterson, P. E., Langston, J. A., Jin, X., Zhou, X., Fisher, A. J., and Toney, M. D. (2005) Kinetic and Crystallographic Analysis of Active Site Mutants of Escherichia coli $\gamma$-Aminobutyrate Aminotransferase, Biochemistry 44, 2982-92.

27. Liu, W., Peterson, P. E., Carter, R. J., Zhou, X., Langston, J. A. Fisher, A. J., and Toney, M. D. (2004) Crystal structures of unbound and aminooxyacetate-bound Escherichia coli $\gamma$-aminobutyrate aminotransferase, Biochemistry 43, 10896-905.
28. Sunko, D. E., Szele, I., and Hehre, W. J. (1977) Hyperconjugation and the Angular Dependence of b-Deuterium Isotope Effects, $J$. Am. Chem. Soc. 99, 5000-5.

29. Bach, R. D., Canepa, C., and Glukhovtsev, M. N. (1999) Influence of Electrostatic Effects on Activation Barriers in Enzymatic Reactions: Pyridoxal 5'-Phosphate-Dependent Decarboxylation of a-Amino Acids, J. Am. Chem. Soc. 121, 6542-55.

30. Jackson, L. K., Brooks, H. B., Osterman, A. L., Goldsmith, E. J., and Phillips, M. A. (2000) Altering the reaction specificity of eukaryotic ornithine decarboxylase, Biochemistry 39, 11247-57.

31. Graber, R., Kasper, P., Malashkevich, V. N., Strop, P., Gehring, H., Jansonius, J. N., and Christen, P. (1999) Conversion of aspartate aminotransferase into an L-aspartate $\beta$-decarboxylase by a triple active-site mutation, J. Biol. Chem. 274, 31203-8.

32. Kochhar, S., and Christen, P. (1988) The enantiomeric error frequency of aspartate aminotransferase, Eur. J. Biochem. 175, $433-8$.

33. Liu, W., and Toney, M. D. (2004) Kinetic and thermodynamic analysis of the interaction of cations with dialkylglycine decarboxylase, Biochemistry 43, 4998-5010.

34. Zhou, X., Jin, X., Medhekar, R., Chen, X., Dieckmann, T., and Toney, M. D. (2001) Rapid kinetic and isotopic studies on dialkylglycine decarboxylase, Biochemistry 40, 1367-77.

BI051475B 